\title{
بين السهل والجبل \\ الحقيقة في تبيان ماهو سامي و غير سامي في كردستان القديمة- بحث في اللغة و الفن-
}

\author{
كوزاد تمُحَّمَ احمد \\ كلية العلوم الإنسانيه، جامعة السليمانية، اقليم كوردستان-العراق
}

(تاريخ القبول بالنشر: 23 شباط، 2021)

الخلاصة

يعتبر الكثير من الكتاب و الباحثين ان بعض المناطق و الاصقاع الواقعة الآن ضمن اراضي كردستان القديمة مواطن لسكن الجماعات

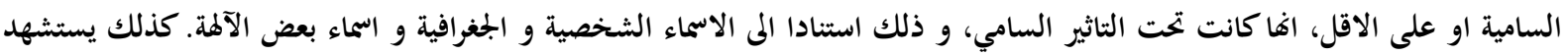

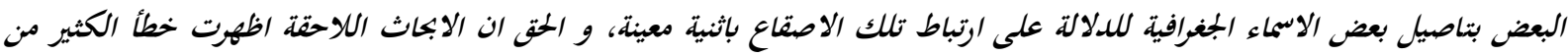

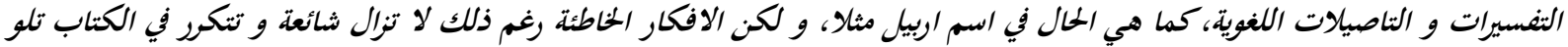
الكتاب و البحث تلو البحث ـ و لم تقتصر تلك الاخطاء على الجانب اللغوي، بل تعدثا المى الجوانب الفنية و الآثار، مما جعل الباحثين الاوائل يعزون ما يعرف بشجرة الحياة المقدسة مثلا المى الآشوربين ليعتبروها من صميم تراثهم. يهدف هذا البحث الى تصحيح البط من هذه الافكار و اعادة الحقوق الى اصحابها ما امكن ذلك. الكلمات الدالة: تاريخ كردستان القديم، العصر الآشوري، أصل الأسماء الجغرافية، اللغه الكردية القديمة

التحليلات تباعا. غير ان اللوم يقع على الكثير من المؤرخين و

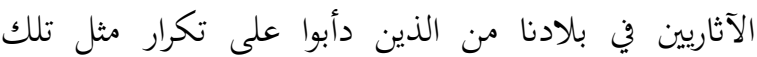
الاخطاء رغم تصحيحها، اما جهالا و غفلة و اما قصدا في بعض الاحيان.

و في حالات اخرى، نجد البعض من الباحثين المختصين

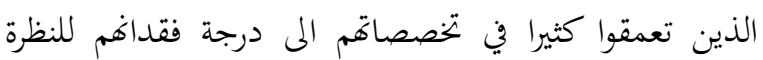
الشمولية، فتراهم ينظرون الى جل الامور من منظار تخصصهم الدقيق و بذلك يسبغون كل ما يمر بكم بصبغة حقل تخصصهم. من هؤلاء على سبيل المثال لا الحصر الباحث ديوران J.-M. Durand المتخصص بنصوص ماري الآمورية، حيث نراه يفسر و يحلل كل الامور على انها آمورية

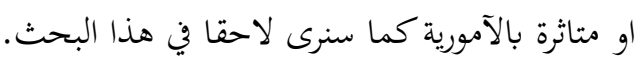

مقدمة

يجدر بنا نحن معشر المؤرخين و الآثاريين في هذا العصر ان نشكر الرعيل الاول من المؤرخين و الآثاريين الذين دشنوا البحث و التنقيب الآثاريين و قراءة النصوص القديمة، حيث

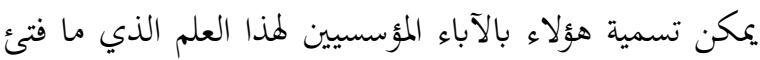

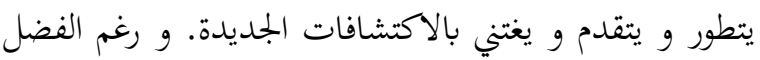

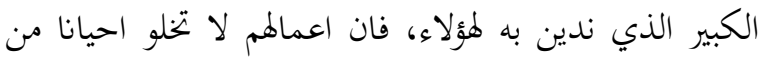
الهفوات و الاخطاء كما هو شأن كل علم و عالم بجتهد. و الحق يقال، لم يكن الذنب ذنبهم او التقصير تقصيرهم في كل الحالات، حيث يعود السبب في العديد من الحالات الى عدم اكتمال الصورة و تسلسل المعلومة و عدم اتضاح السياق التاريخي. الا ان الاكتشافات المتواصلة و الدراسات المهنية الدؤوبة صححت الكثير من مثل تلك الاستنتاجات و 
سلالة اور الثالثة بحوالي القرن و نصف القرن و قد ورد فيها

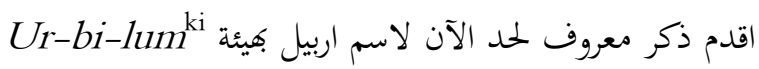
(Kutscher, 1989, 59) عصره تحكم من قبل انسي Ensi (اي امير او حاكم) يحمل

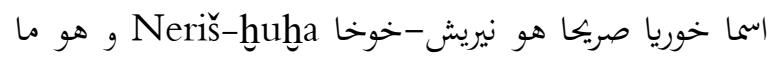
يجملنا على الاعتقاد بقوة ان سكان المدينة في هذا هوريت العصر كانوا من الخوريين ايضا. و اذا ما اسقطنا عن صيغ الاسماء المذكورة لاسم اربيل

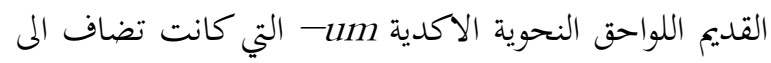

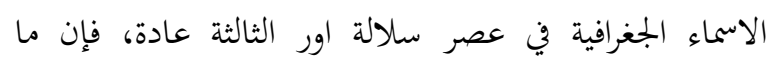

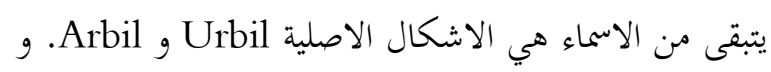

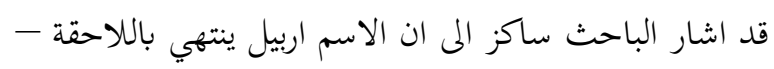

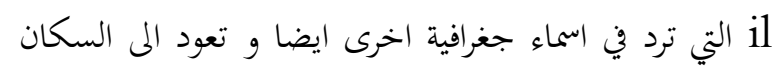

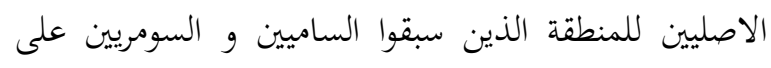
حد سواء و يمكن ملاحظتها في اسم مدينة آشور القديمة

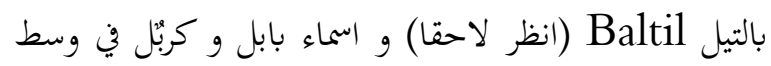

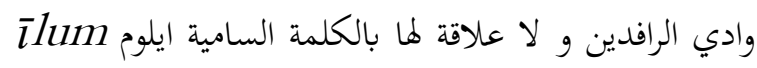

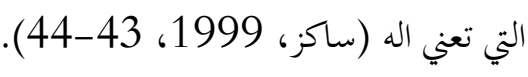

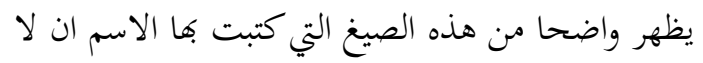
علاقة لها باربعة آلهة، خصوصا و انه لايوجد لها صيغة كتابة التهب

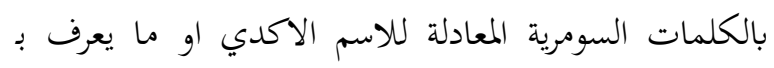
logogram من قبل الكتبة الآشوريين لكتابة الاسم بعلامتين مسماريتين

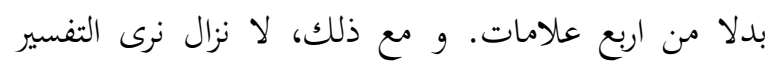
القديم في العديد من الكتب و المقالات و المنشورات الحمديثة. 2- كم كانت المدن الآشورية الثلاث آشورية؟:

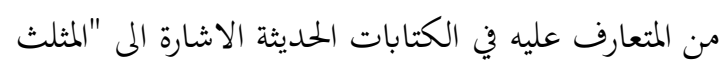

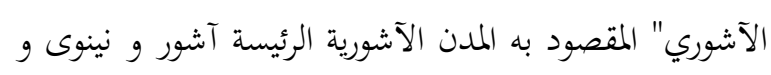
اربيل. لقد سلَم الباحثون المحدثون فيما يبدو تسليما كليا

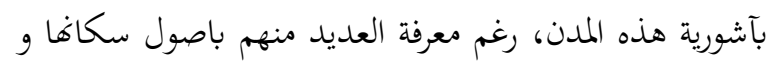

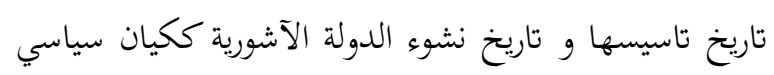

\section{1- اسم اربيل:}

كان من اوائل ما اكتشف من نصوص مسمارية في بلاد

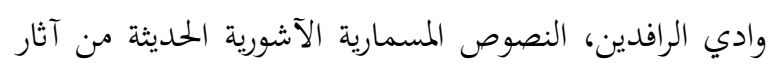

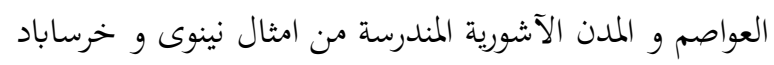

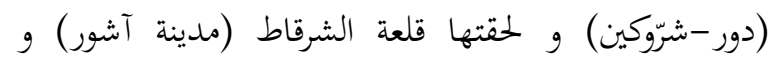

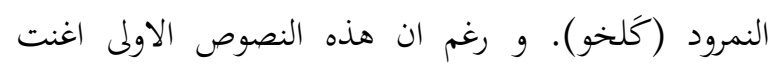

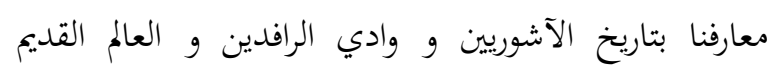

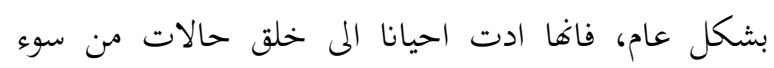
الفهم. و ابرز مثال على ذلك كتابة اسم مدينة اربيل.

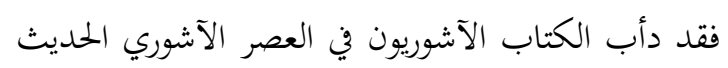

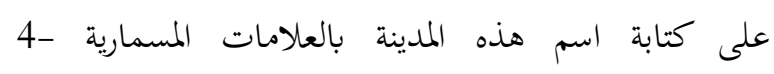

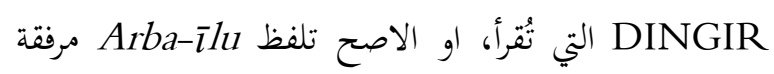
دائما بالعلامة الدالة على اسماء المدن. ان القارئ لهذا الاسم

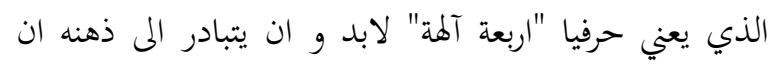

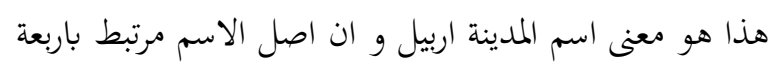

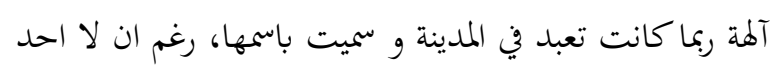

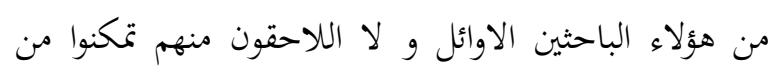
تحديد تلك الآلهة الاربعة او يجدوا لها ذكرا في الاوتل ولئ النصوص، ناهيك عن العثور على آثارها المادية من تماثيل او معابد.

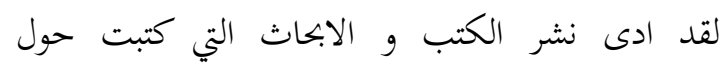

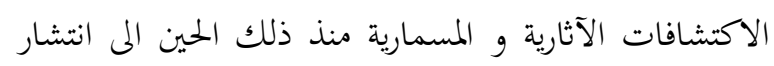

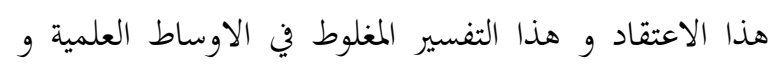

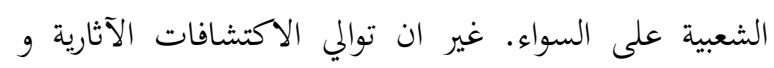

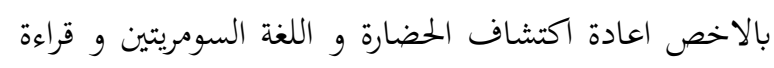
نصوصها، عرّفت الباحثين على صيغ اقدم لكتابة اسم اربيل،

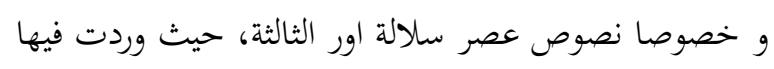

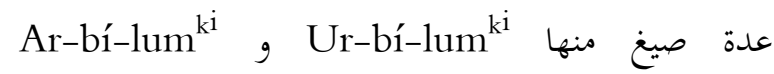
(Edzard \& Farber, 1974, 217) Ur-bíl-la ${ }^{k i}$ ورعة فربة Ur-ì-bí-lum ${ }^{k i}$, Ur-bí-ì-lum ${ }^{k i}$

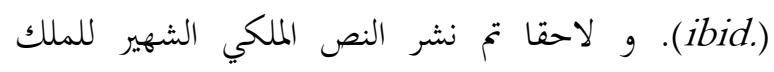

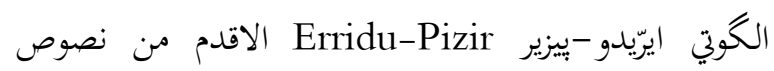


سكان هذه الطبقة H التي حوت هذا المعبد اناسا سلميين

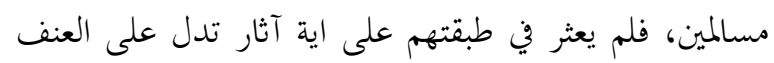

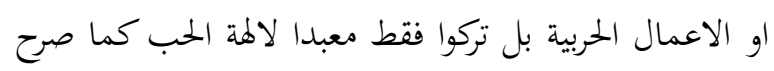

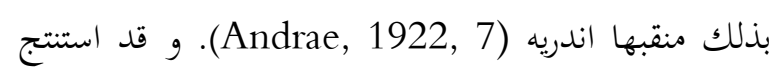

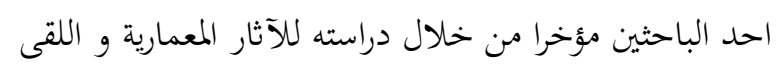

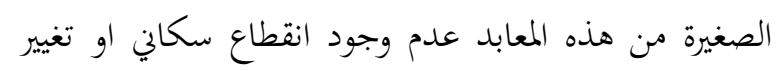

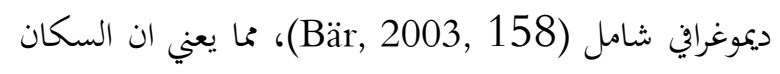
الذين انتجوا آثار الطبقات القديمة، استمروا في التواجد و في التاني

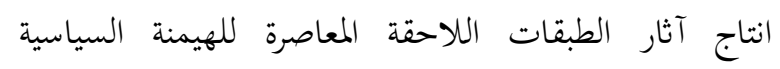

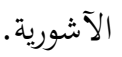
و لا يقتصر الامر على العمارة فقط، بل ان كسرة من

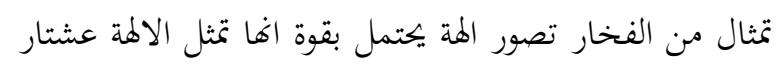
نفسها، حيث عثر عليها في معبد عشتارنفسه، تحمل ملامح

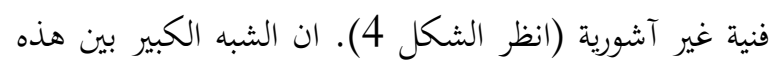

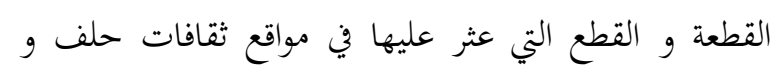

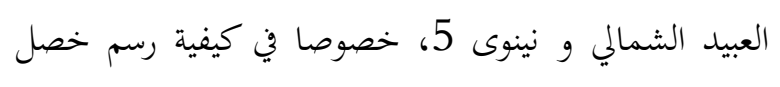

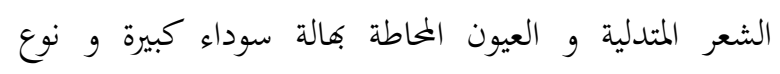
الملابس، تحملنا على الاعتقاد و بقوة اها قطعة تعود المى ثقافة

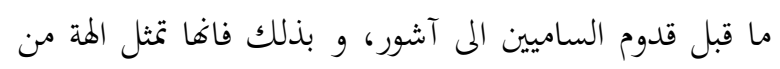
آلهة تلك الثقافة و ذلك القوم و من المنطقي ان تكون الهة الهن

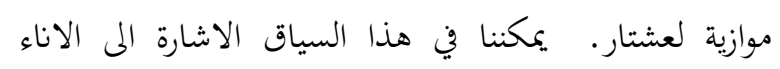

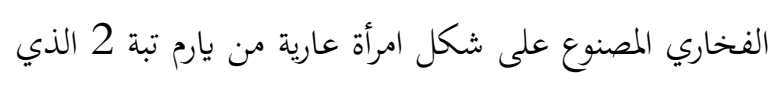
Forest, ) يعود الى عصر حلف (الالف السادس ق.م.

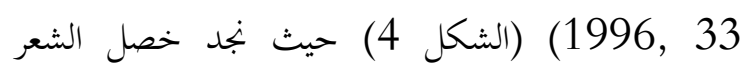

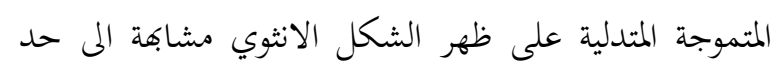

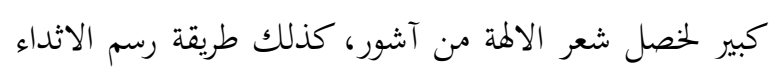

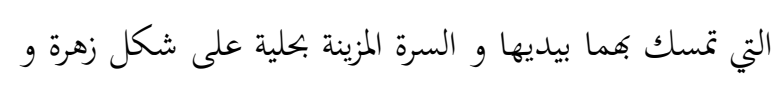

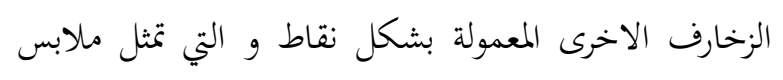
اضافة المى الحلقات المرسومة حول العضدين و التي ربما تمثل معاضد ربما كانت ترتديها النسوة في تلك الازمان، كلها تتشابه مع بعض الى حد كبير رغم المسافة الزمنية الكبيرة بين
في العصور اللاحقة. و مع معرفتنا بان هذه المدن الثلاث كانت خاضعة لحكم الدولة الآشورية في العصر الآشوري الحديث و ان اثنتين منها على الاقل كانتا عاصمتين آشوريتين

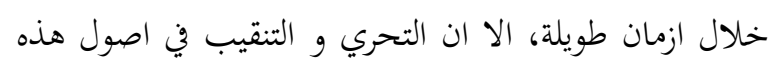

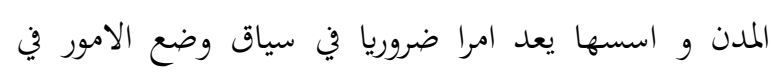
نصابها و تبيان حقائق التاريخ.

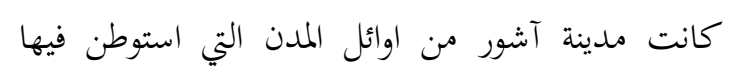

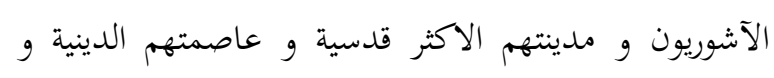

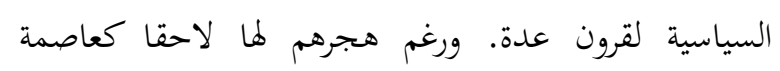

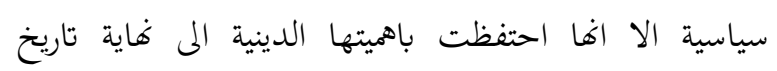
الآشوريين السياسي. و لكن الحقيقة هي ان المنطقة ككل

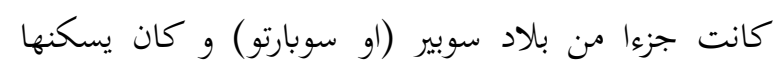

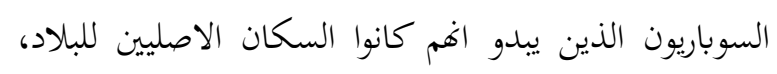

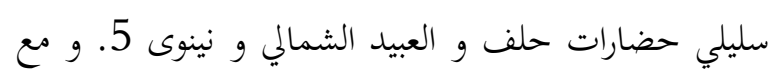
ذلك فقد اختلطوا مع الخوريين منذ زمن ظهورهم على مسرح

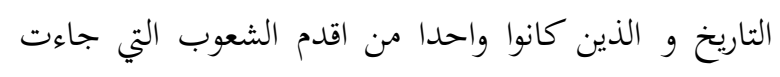

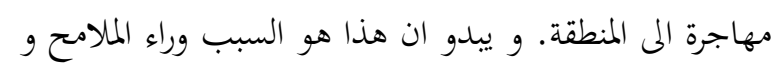

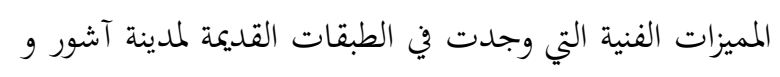

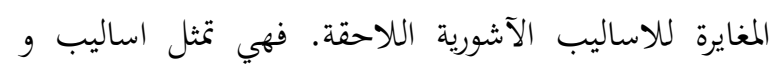

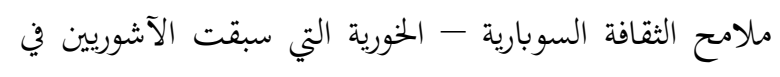

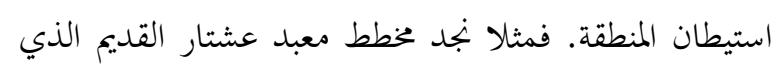

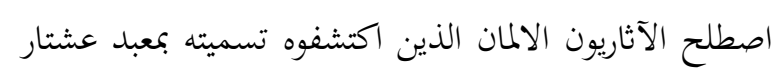

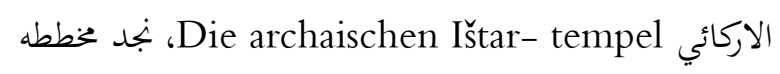
مطابقا لتخطيط معابد ثقافة نينوى 5 و معابد كردستان القديمة، حيث يتكون من خلوة طولية يقع مدخلها في الجدار

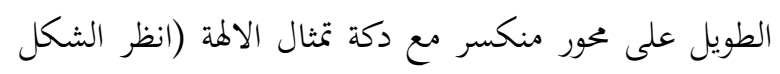

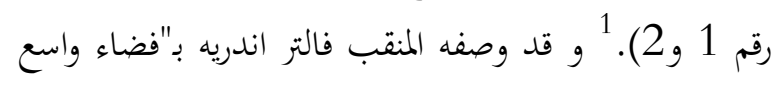

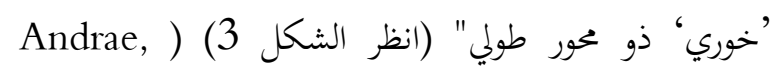

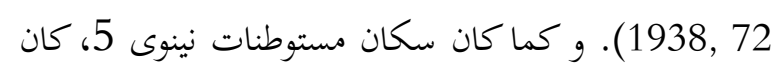

$$
1 \text { حول نماذج من هذه المعابد ينظر: }
$$

Roaf, 2003, 33, fig. 1; Damirji, 1987, figs. 45, $109,119$. 
Lewy, ) الاخلامو." و يضيف للتوضيح: "نخن سوبارتو

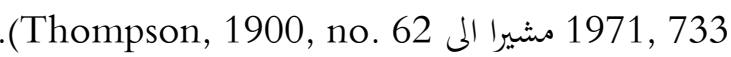
اما حول معنى اسم بالتيل، فقد ذهب البعض الم انه اسم

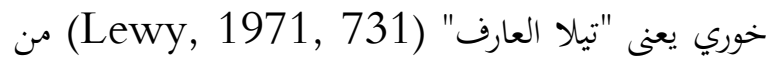

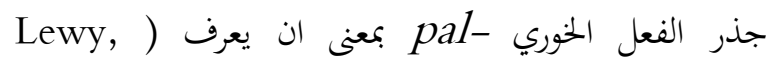
(1971, 732; Wegner, 2000, 236 البعض الآخر ان المقطع الاخير من الاسم، اي 'ايل 11' يعود

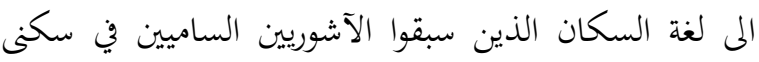

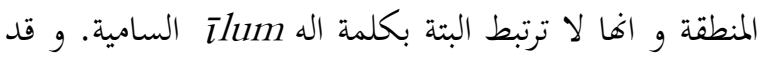
سبق و ان اشرنا الى التفسير الذي تقدم به ساكز حول النه اللاحقة il- التي ينتهي بها هذا الاسم و نسبته الى القوم

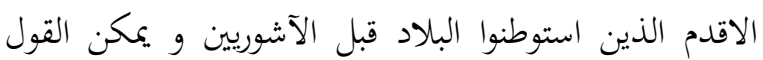

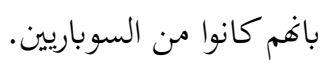
و هنا يجب الالتفات الى مدينة نينوى. فاذا كانت آشور التي تقع الى الجنوب من نينوى اولا و على الضفة الغربية

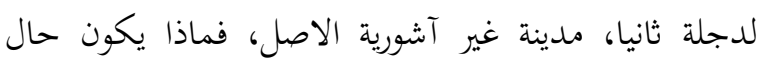
نينوى الاقرب الى بلاد سوبارتو و بلاد الخوريين؟ كانت نينوى، و كما اظهرت الدلائل الآثارية احدى مراكز ثقافة بادة الحريني

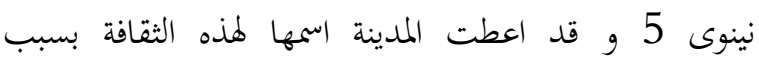
اكتشافها لاول مرة في خرائبها على يد الآثاري البريطانى

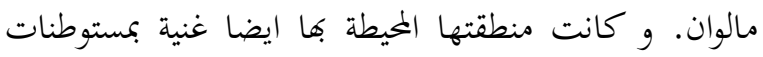
تلك الثقافة حيث عثر على العديد منها خلال التنقيبات الانقاذية التي جرت في منطقة حوض فايدة و اغنت معرفتنا بآثارها (ينظر :Rova and Weiss, 2003). و قياسا على اربيل في العصر الكوتي التي كانت تحكم من قبل حاكم خوري، نجد نينوى في عصر سلالة اور الثالثة تحكم من قبل حاكم خوري ايضا و اها كانت امارة او دويلة و ان كانت تابعة او موالية لسلطة اور. كان اسم هذا تها الحاكم تيش-اتال Tiš-atal الذي نعرف عنه من خلال نال نص شهيه

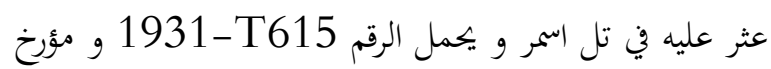

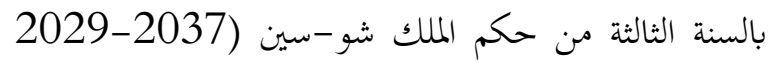

القطعتين، الا انه من الواضح ان القطعتين تنبعان من مصدر فني واحد و من تقاليد دينية مشتركة.

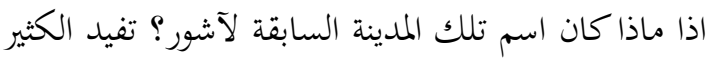

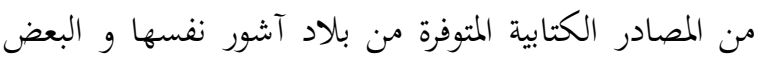
منها من بلاد بابل، بان المدينة كانت قبل هجرة الآشوريين

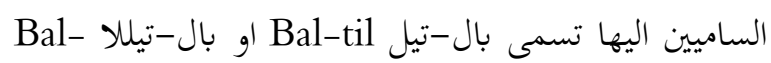

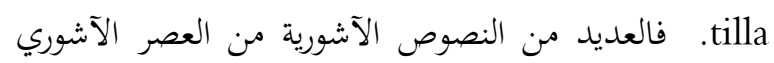
الحديث، تشير الى ان بالتيل كانت السلف الاقدم للمدينة (Lewy, 1946, 405ff.) (555-539 ق.م) على مسلة عثر عليها في بابل يؤيد هذا

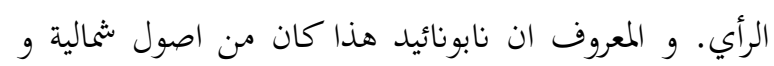
بالتحديد من مدينة حران التي كانت تتبع للامبراطورية

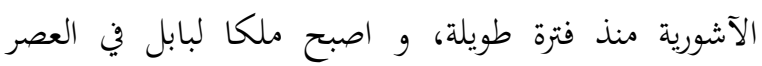
البابلي الحديث اثر انقلاب قام به هو و رهط من اصحابهابه (انظر حول ذلك: Dandamayev, 1998-2001, 7). يروي نابونائيد في هذا النص كيف ان الاله مردوك، الاله

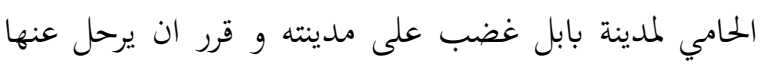

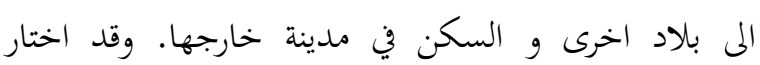
مردوك لمسكنه المؤقت حسب هذا النص مدينة بالتيلا في بلاد

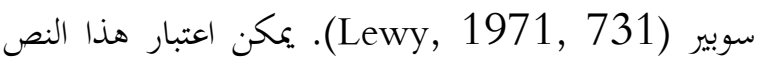
دليلا على ان مدينة آشور كانت تسمى بالتيل في الوقت

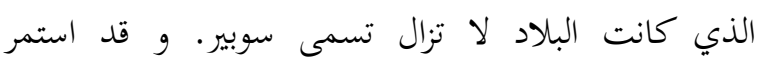

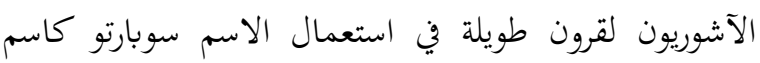
لبلادهم في نصوص التنجيم من اصل بابلي، و ليس في

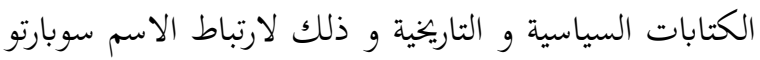
او تشاهه مع الكلمة الدالة على العبيد. و قد ورد وتدات تاكيد كتابي صريح على ان المقصود ببلاد سوبارتو كان بلاد آشور

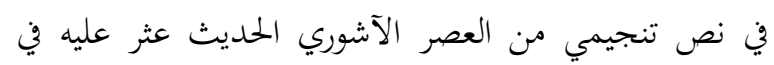

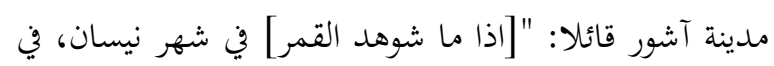
اليوم الثلاثين منه، [فان بلاد سو]بارتوم [سوف تفني] 
تستعصي امراضهم على العلاج كما نعرف ذلك من الرسالة

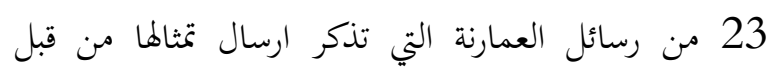

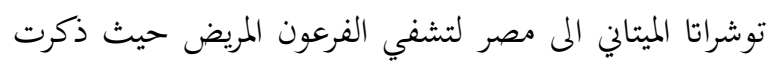

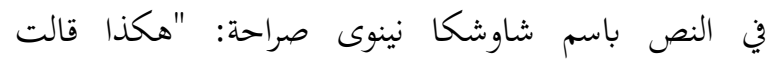

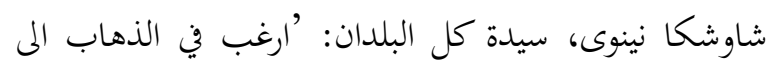

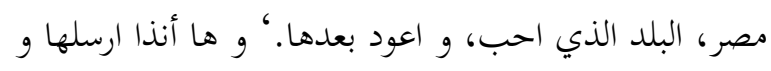

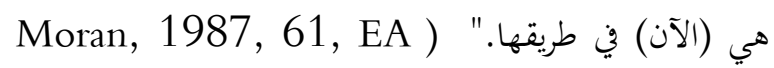

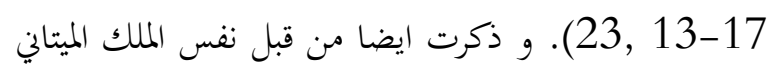

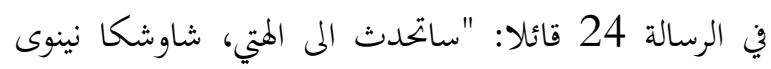

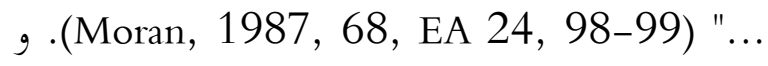

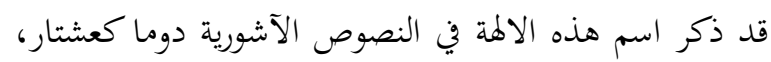

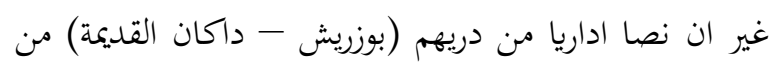

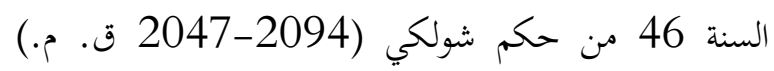

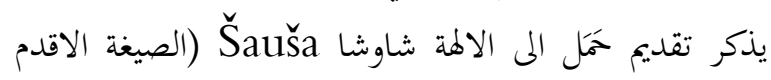

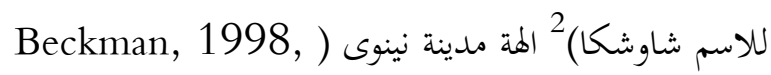

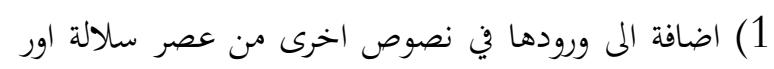

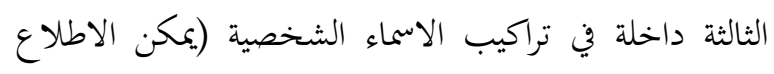

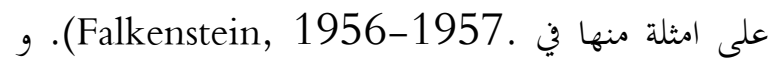

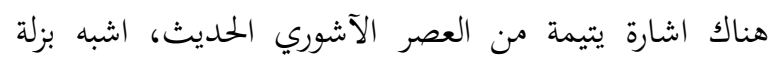

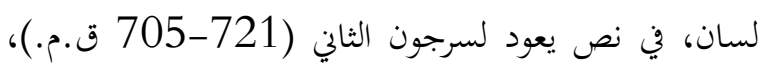

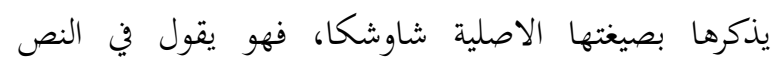

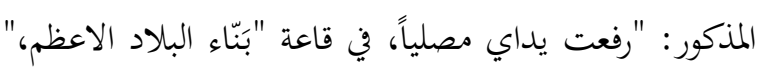

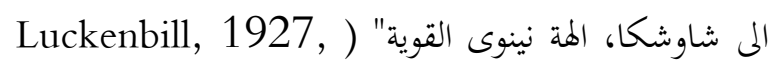

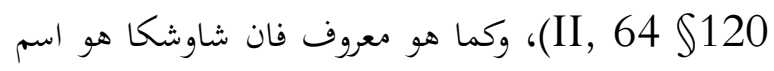

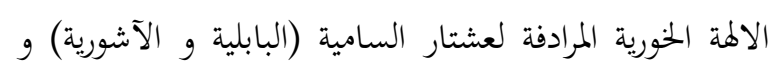

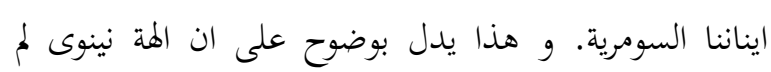

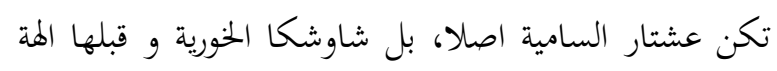
السكان الاصليين الاقدم من الخوريين، و لكن الآشوريين آثروا

2ح حول الصيغ الاملائية المختلفة لكتابة اسم شاوشكا في نصوص اور

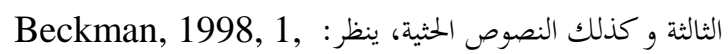

note $4 ; 5$.
ق. م.) ملك سلالة اور الثالثة. يذكر النص ان تيش-اتال

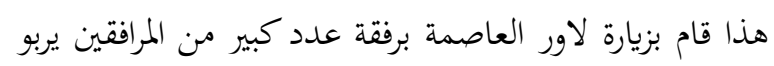

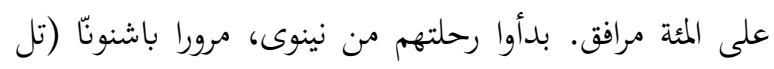

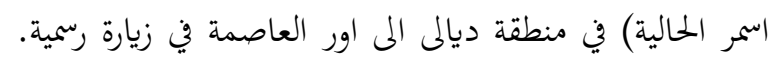

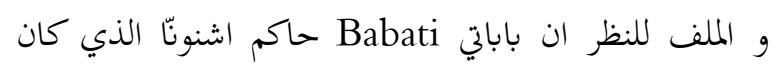

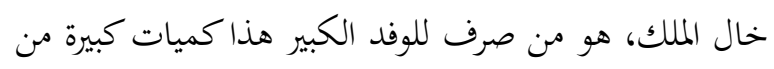

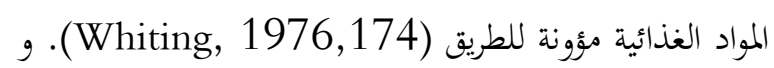
هذا الامر يشير الى ان سكان نينوى، او غالبيتهم على الاقل، المان.

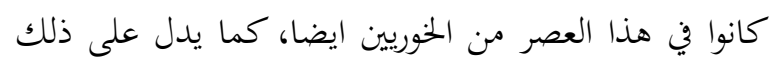

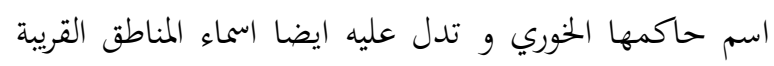

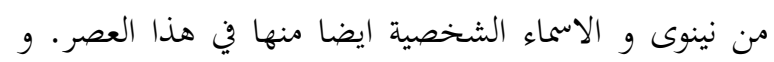
قد اشتهرت نينوى ايضا باها كانت مسكن الألمة المعروفة

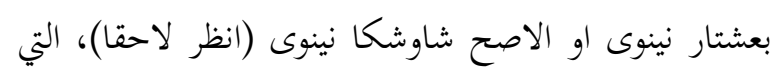

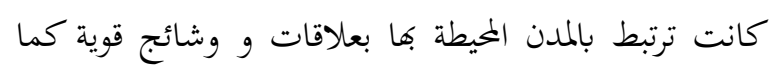

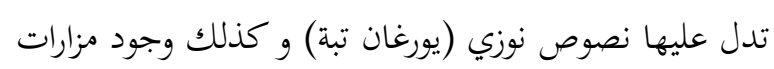
عديدة لعشتار نينوى في البعض من المدن الخورية. فهناك مثلا

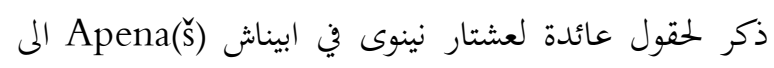

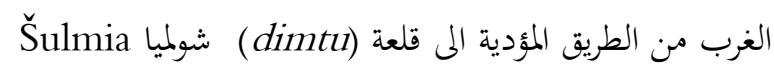

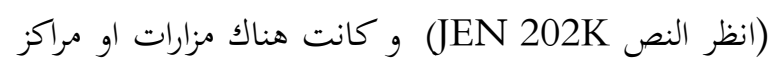

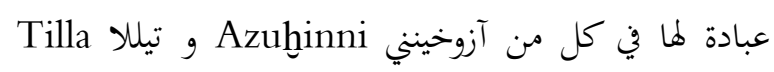

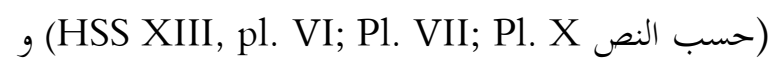
HSS XIII Pl. VI; حسب النص (حسل) Hilmani خيلن Pl. VIII SMN 588; Pl. X لعشتار نينوى كانت تأتي من اولامي HSS ) Ulamme (Fincke, 1993, 188) (XIII Pl. VII SMN 799 غير ان المشكلة هنا تكمن في الاسم عشتار المنسوب الى الى المال

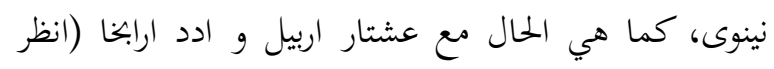
لاحقا).

كما هو معروف فان الالهة عشتار نينوى كانت الهة الهان شهيرة و مبجلة طوال العصور الآشورية كوها احدى الآلهة

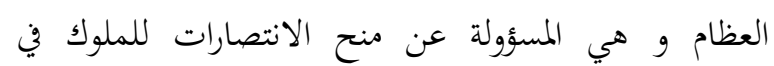

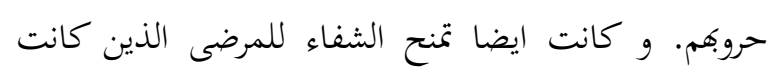
kozad.ahmad@univsul.edu.iq 
خصوصا و انها تقع تحت اسس معبد عشتار التالي الذي بني

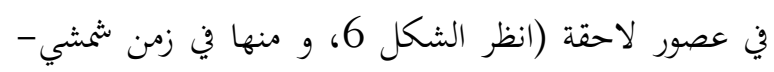

ادد الاول (انظر: . Reade, 2005, 347ff.).

\section{3- 3كام آشور الاوائل:}

في نفس هذا السياق نجد قائمة الملوك الآشوريين تورد التواتي:

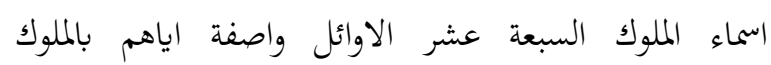
الساكنين في الخيام مما يعني ان هؤلاء حكموا في (Poebel, 1942, 252)

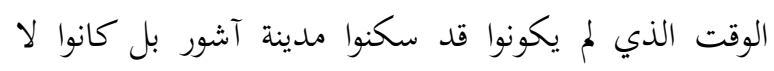

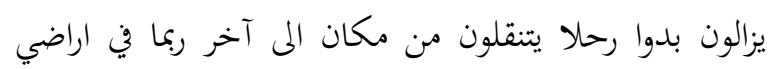

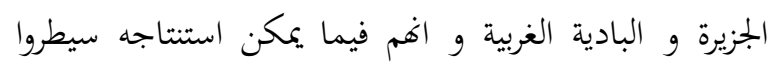

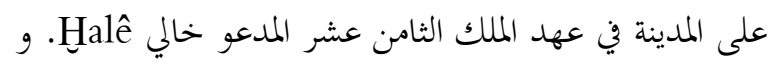

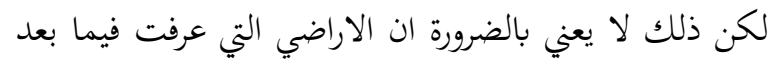
ببلاد آشور قد اصبحت آشورية كليا مع سيطرة الآشوريين

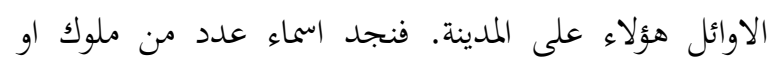

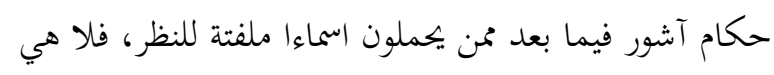

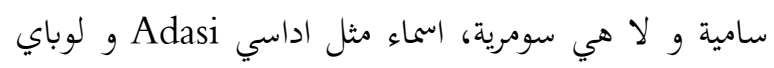
Lubai

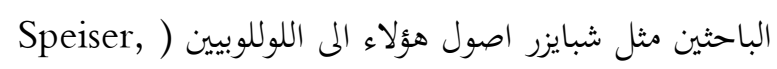
(1930, 90, n. 8

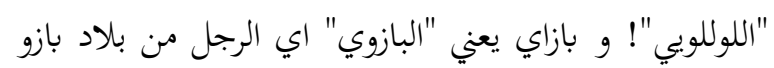
Bazu الاسماء اللولوبية (.Speiser, ibid). و رغم ان قائمة الملوك الآشوريين هذه تصف اداسي بانه مغتصب للعرش مستعملا

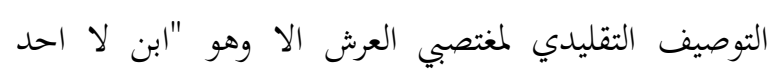
Grayson, 1980-1983, ) "mār lā ma-ma-na

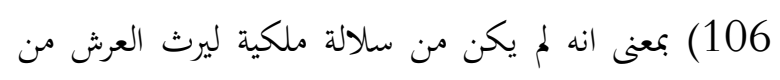

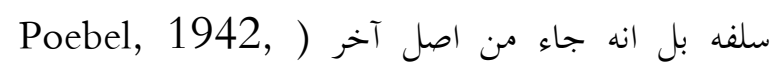

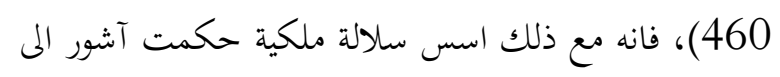

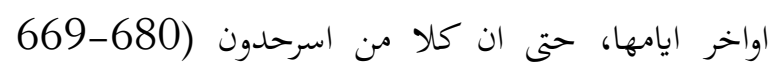

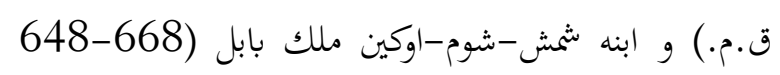

بعد سيطرقم على المدينة استعمال الاسم السامي المرادف لها

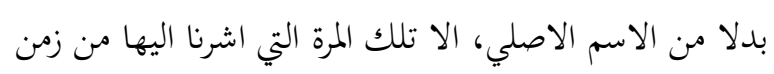

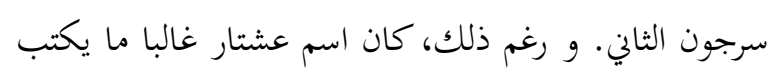

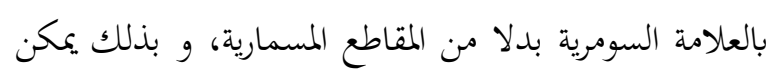

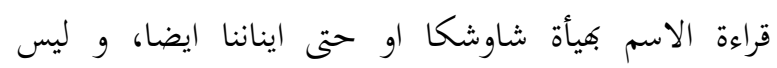

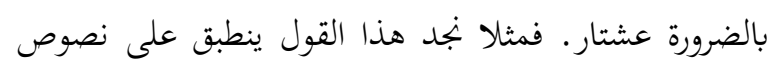

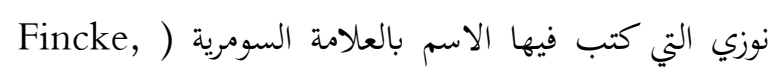

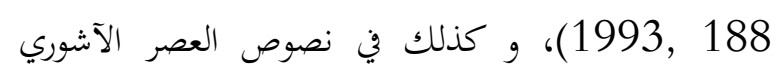

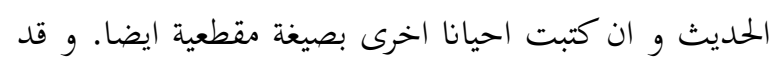

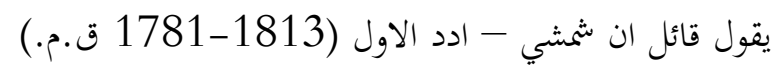

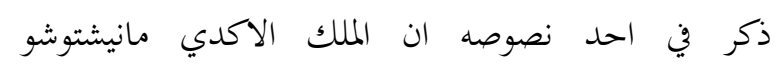

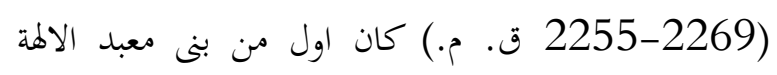

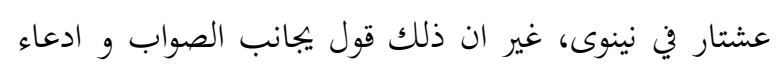

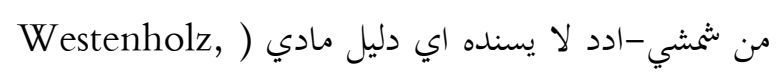
2004, 7; Beckman, 1998, 2 المادية التي اكتشفت هناك تدل على ان الالهة و معبدها اقدم من ذلك بكثير، حيث وجدت و وعبدت هذه الالمة، طبعا

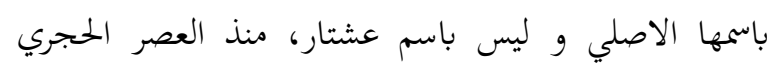

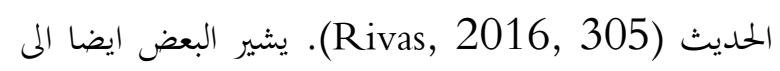
ان قدوم الخوريين الى نينوى ربما لم يسبق الاكديين بفترة طويلة

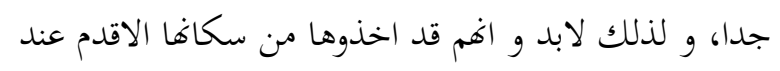
استيطافم في نينوى. و نفس الكلام يصح بالنسبة لمعبدها ايضا الذي كان اقدم من ذلك بكثير، يكفي ان تخطيطه كان

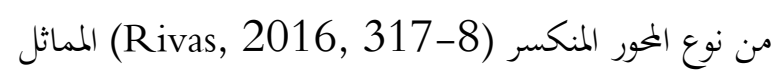

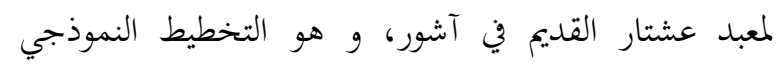

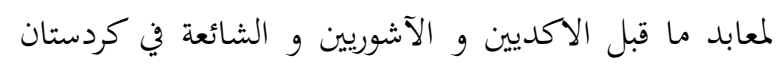

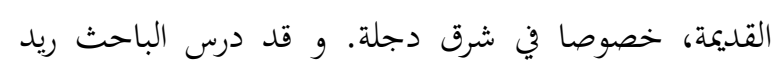

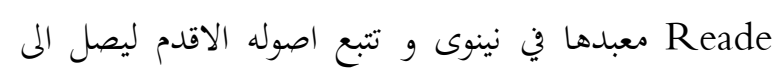

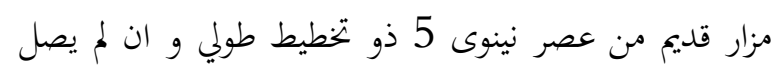
بشكل كامل، و لكنه يرحج كثيرا ان يكون السلف الاقدم

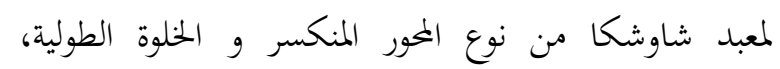


القديمة) و اغلبها وصولات و جرايات و ما شابه. ظن الباحثون اول الامر ان اسم سو يشير الى السوتيين لورود

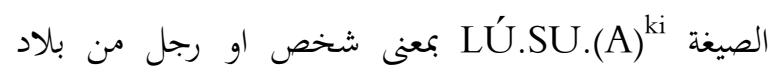
سو(ا) كما ظن كريمر، او بلاد سوبارتو كما اقترح كيلب

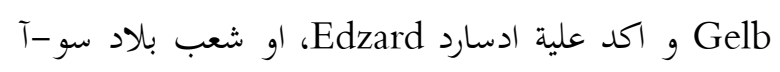

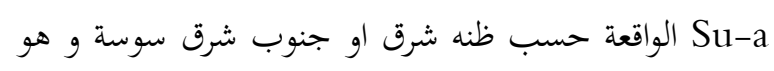

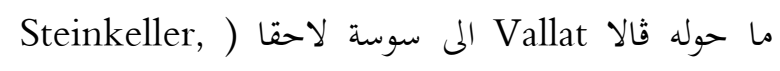
8-1988, 197). و و على اساس هذه التفسيرات، خصوصا مطابقة الاسم LÚ.SU.(A) مع سوبارتو بنى البعض منهم

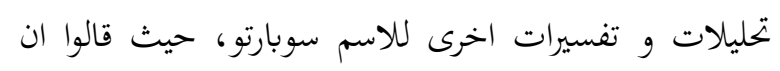

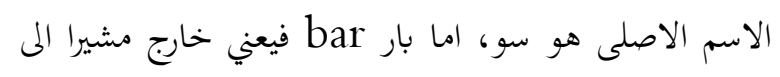

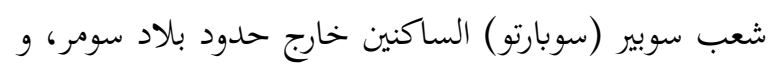

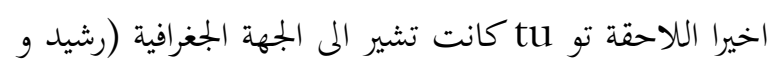

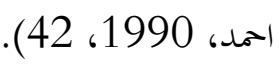
غير ان دراسة دقيقة لهذا الاسم و سياق وروده في الوثائق

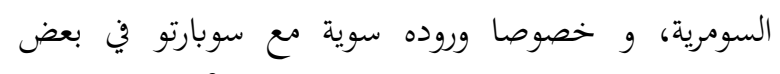

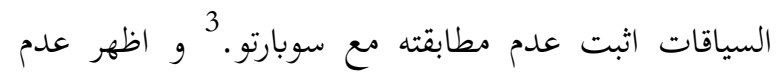

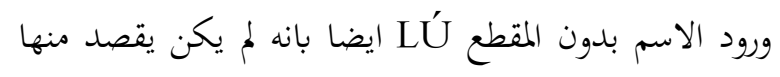

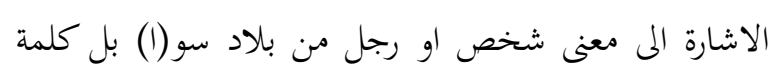

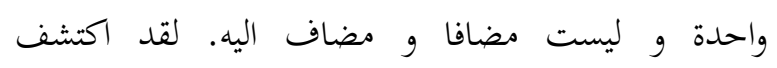

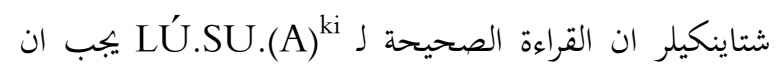
تكون LÚ.KUŠ(.A) التي تعكس التأصيل الشعبي للكلمة

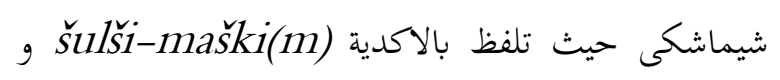

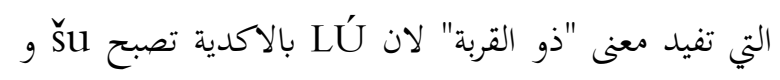
(Steinkeller, 1988, 198) maškum تصبح التعربح لتكون النتيجة المقصود منها بلاد سيماشكي او شيماشكى في غرب جبال زاكروس الوسطى. و من بين ما يؤكد اهما كانت صيغة املائية ابتكرها كتاب يوزريش-داكان لـان للاشارة الى بلاد سيماشكي ان اسم هذه البلاد لم ترد بالصيغة العادية

3u- انظر مثلا القائمة الجغرافية من العصر البابلي القديع الذي يعدد bir $_{4}{ }^{\text {ki }}$, Su-ti-um ${ }^{\text {ki }}$, LÚ.SU ${ }^{\text {ki }}$ (MSL 11, p. 60, 1. 22-
ق.م.) بعد قرون عديدة يرجعان اصولمما المى جدهما الاكبر

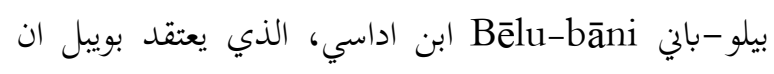

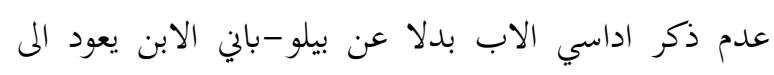

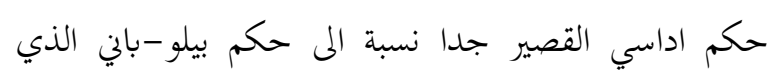

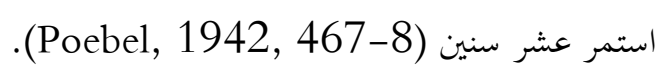
مهما يكن من امر، فان وجود اشخاص، سواء كانوا فعلا

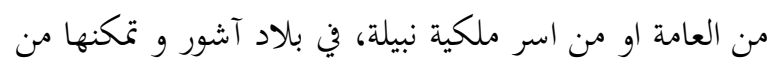

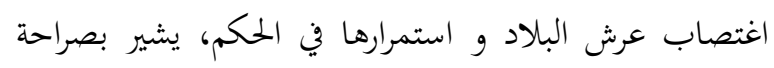

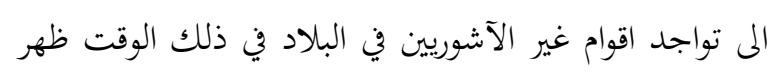

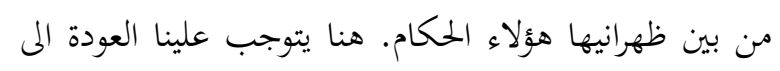

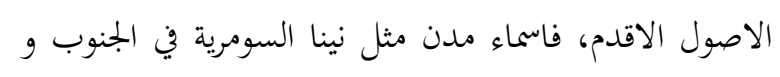
نينوى في الشمال، و كلاهما مرتبط بالسمك (حيث كانت

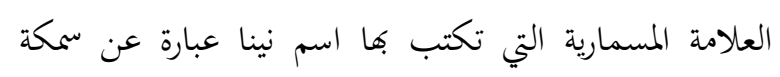

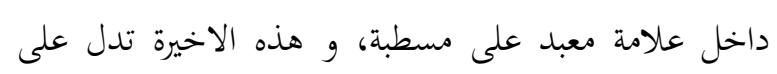

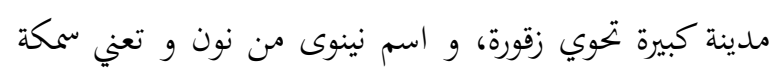
او حوتا) و كذلك اوروك الجنوبية و اوركيش (تل موزان)

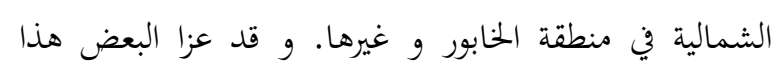

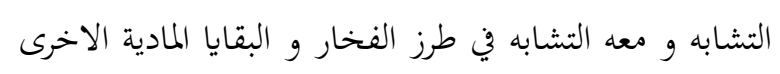

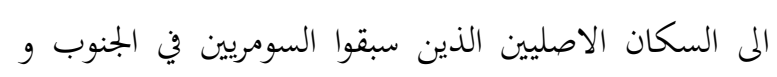

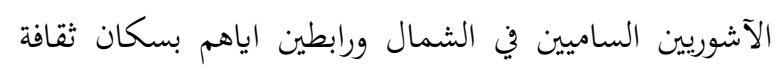

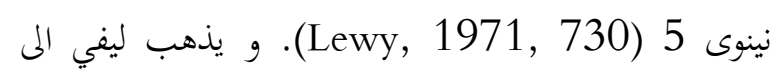
القول بان السكان الاصليين لبلاد آشور هؤلاء الذين يسميهم

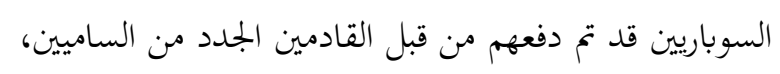

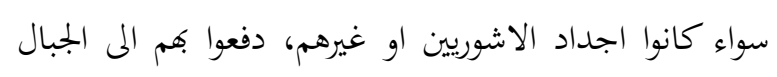

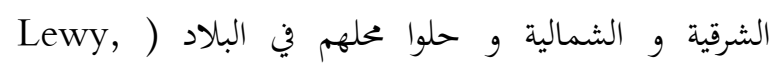
(1971, 733 رغم بقاء البعض منهم بين الآشوريين. 4- بلاد سو و شعبها السوئيون: و في حالة مشابهة لاربيل، ظهر في العديد من وثائق

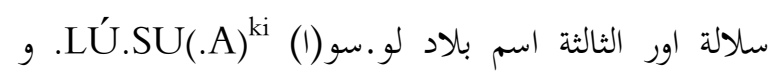
كانت هذه الوثائق من الوثائق الادارية و الاقتصادية التي جاءت من تل دريهم (بوزريش-داكان Puzriš-Dagan 
و قد برز من بين هؤلاء الزعماء اللوللوبيين في حملته الاولى

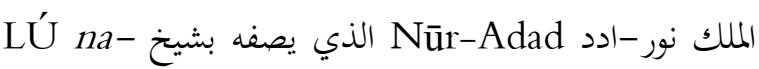
Dagara si-ku ساميا لا يقبل المورابة او الشك و يعني نور الاله ادد اله هواله

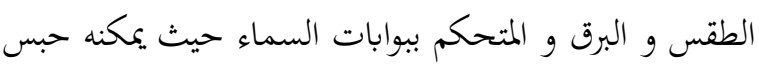
الامطار او اطلاقها، و هذا الاسم الشخصي السامي في هذا لئمات

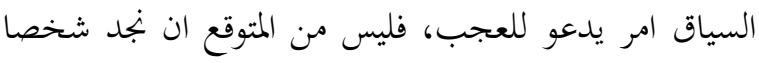
يحمل اسما ساميا يهكم قوما غير ساميين في منطقة معزولة الى لى حد ما و بعيدة عن النفوذ السياسي المباشر للدول السامية.

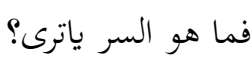
عند العودة الى النص المسماري الاصلي للحولية نجد اسم اسم المبا

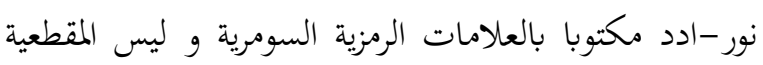

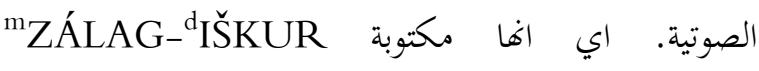
(Grayson, 1991, 244, A.0.101.17)، و من المعلوم ان هذه العلامات الرمزية تكتب بالسومرية و لكنها تقرأ في سياقها حسب اللغة الاصلية. اي يمكن قراءقا باللوللوبية كما

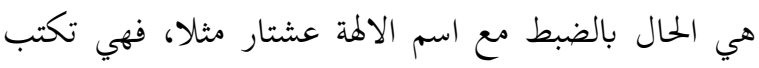

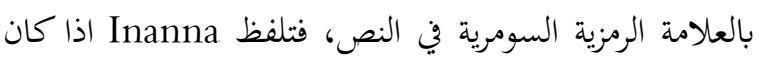
النص سومريا او اذا كان الحديث يدور حول الالهة السومرية

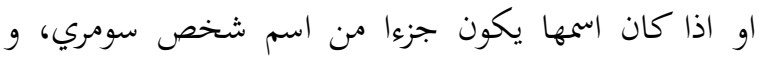
تلفظ Ištar اذا كان النص اكديا او كان المقصود الالهة الاكدية بالبابلية في البيئة السامية او اذا كان اسمها يكون جزء النها

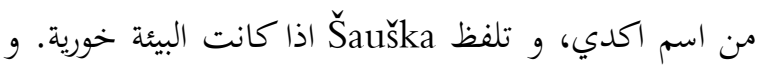
هكذا، فإنه لايمكننا قراءة هذا الاسم الشخصي على انه اسم

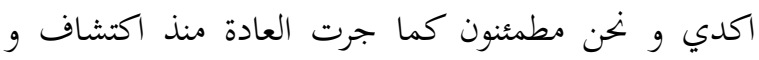
قراءة النص، بل يجب علينا مراعاة البيئة اللغوية و الاثنية

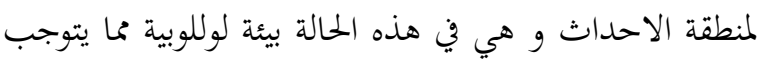

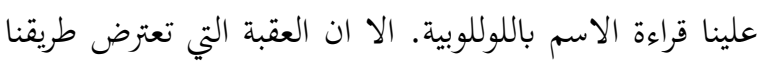
هنا هي اننا لا نعرف لغة القوم و لا نعرف ماذا كانوا يسمون اله الطقس الخاص بكم، لذلك نضطر الى كتابة و قراءة الاسم
ولا مرة واحدة في نصوص يوزريش-دi-maš-ki ${ }^{k i}$ رغم العلاقات و التداخل السياسي و غير السياسي في هذا العصر بين سومر و سيماشكي. لقد خلصت الدراسة ايضا الى ان ورود هذا الاسم يقتصر على عصر سلالة اور الثالثة

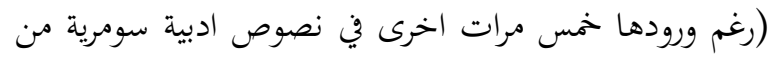

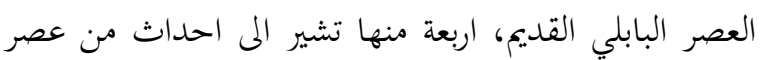
سلالة اور الثالثة و في قائمتين جغرافيتين من العصر البابلي القديم) (Steinkeller, 1988, 197). 5- نور -ادد، زعيم اللولوبو!

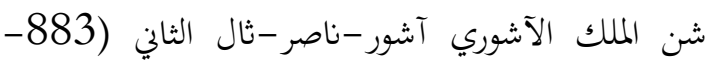
859 ق.م.) حملاته العسكرية على بلاد زاموا، موطن القوم المعروفين باللولوبو(م) او اللولو Lullu في سنوات حكمه بحديه الاولى. وبغض النظر عن حجم الدمار و الدماء التي اسالها

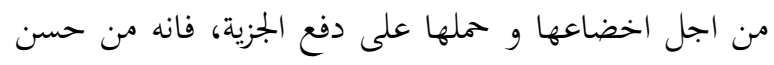

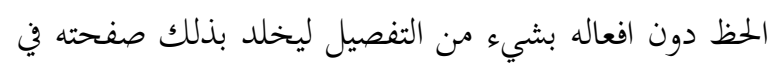

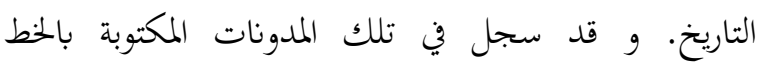
Standard المسماري و و اللغة الاكدية النموذجية Babylonian الشخصية التي افادت الباحثين المحدثين كثيرا في تحديد تلك

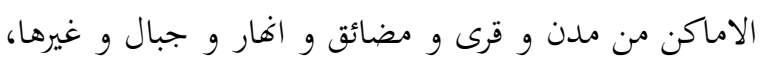

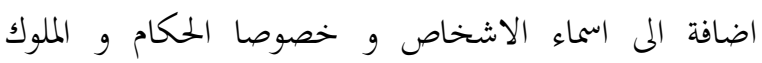

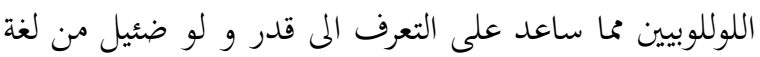
القوم. و قد قام بذلك و بجدارة الباحث الرائد في هذا المجال

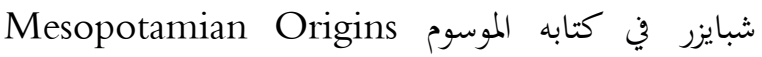
"الاصول الرافدينية" (Speiser, 1930) كما قام بدراسة تاريخية - عسكرية - جغرافية لمسار حملات هذا الملك في

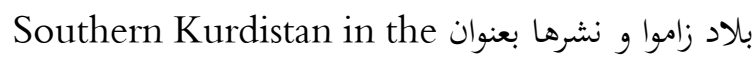
"كردستان Annals of Ashurnasirpal and Today الجنوبية في حوليات آشور - ناصر - بال و اليوم." (Speiser, 1926-7) 
الى سكان المدينة الخوريين كما تفيد النصوص المسمارية

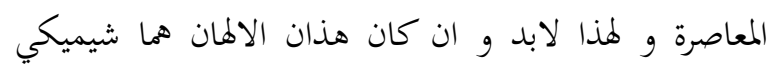
Seššup Šimegi

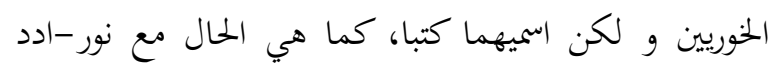

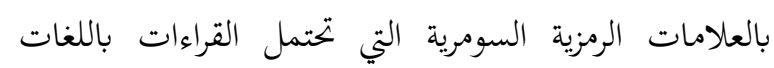
المختلفة. و قد ايد هذا الرأي كل من الباحثين ديوران و و شاربان Charand البابلي القديم ( Charpin and Durand, 1985, .(315, n. 99

\section{7- - - زازوم و نولدانوم و نوزو:}

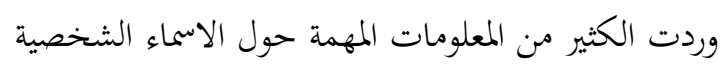
و اسماء الاقوام و القبائل و الاسماء الجغرافية اضافة الماتل

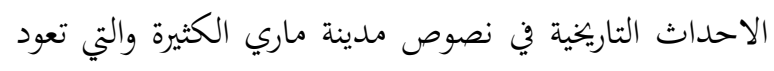

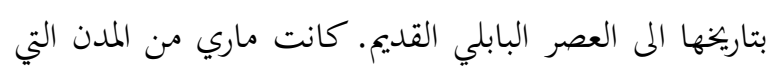

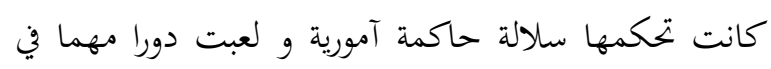

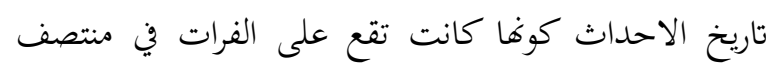
الطريق تقريبا بين بلاد بابل و بلاد آشور و الدويلات السورية في الغرب. كا من سوء حظ سكانها و من حسن حظ علماء

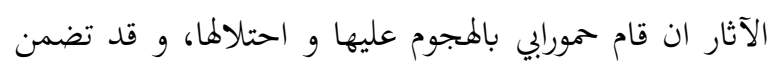
ذلك الهجوم احراق قصرها الملكي الذي ادى المى دفن ارشيفها

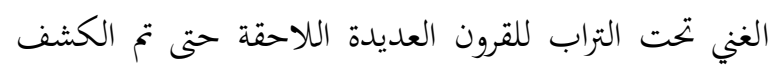
عنها في بدايات القرن العشرين على ايدي المنقبين الفرنسيين.

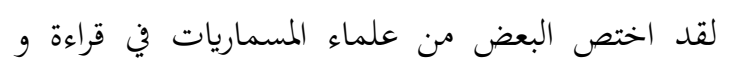

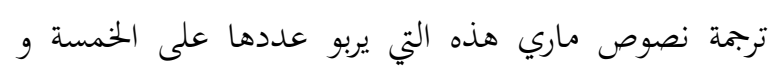

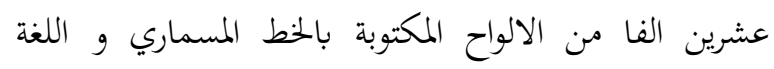

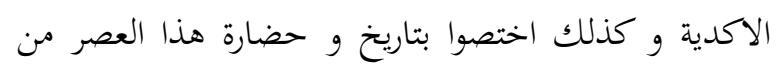

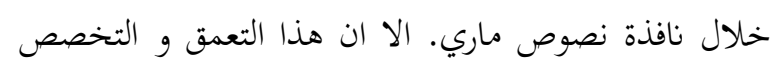

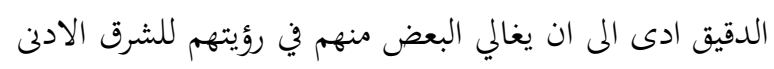

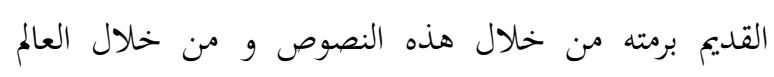
الآموري الذي وفر ارشيف ماري لهم مادة غزيرة، فباتوا

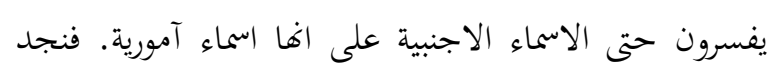

بالرموز السومرية المى اليوم الذي نكتشف فيه نصوصا تفيدنا في معرفة تلك الاسماء و الكلمات بلغتها الاصلية.

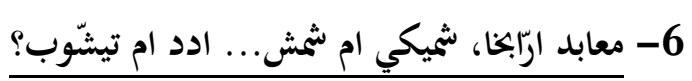

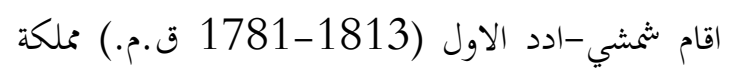
في شمالي بلاد وادي الرافدين في الاراضي التي تشكل حاليا

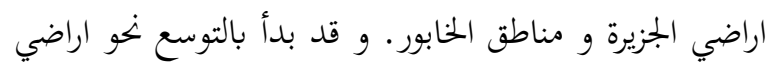

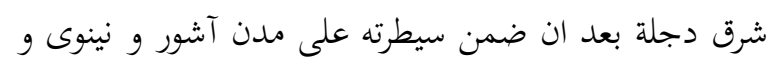

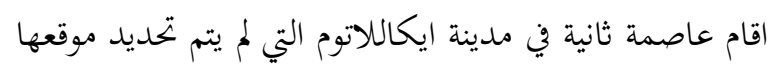

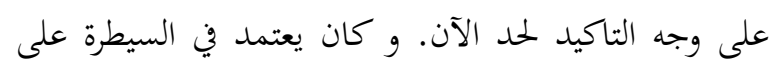
هذه الاراضي على تحالفه مع مملكة اشنوننا في منطقة ديالى، ونل،

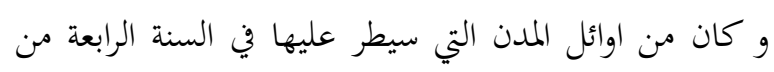
تسنمه الحكم (1781 ق.م.) في شرق دجلة مدينة ارّابخا Charpin, 2004, 165, n. 50; Charpin and ) (Ziegler, 2003, $145 f f$

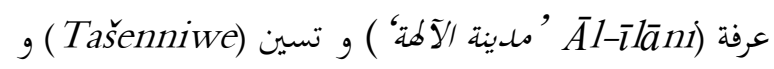

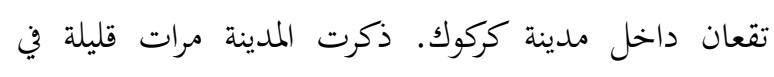

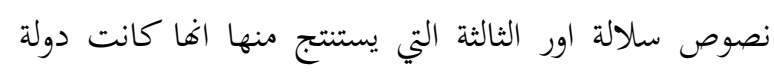

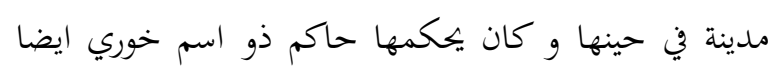

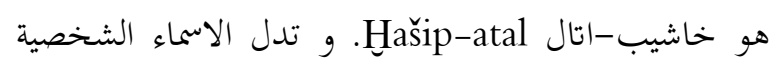
المرتبطة بالمدينة و خصوصا تلك المدونة في نصوص نوزي ان سكاها كانوا من الخوريين (Ahmed, 2012, 345). لكن ذكرها ازداد خلال العصر البابلي القديم. و ما ما يهمنا هنا هو ذكر شمشي-ادد في نص المسلة التي كتبها تخليدا لانتصاره

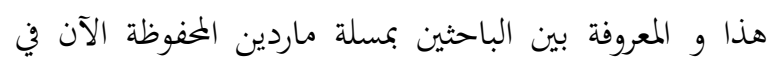
متحف اللوفر، مشاركته في عيد الدفء كما يسميه و تقديمه

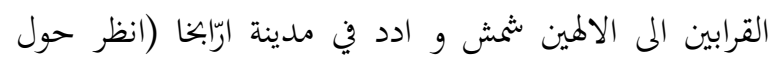

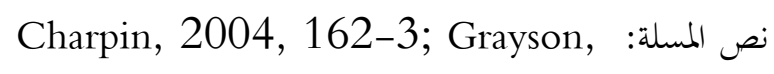
65-1987, 64). هنا ايضا يبرز السؤال ما اذا كان اسم

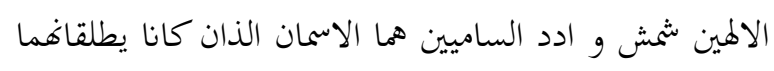

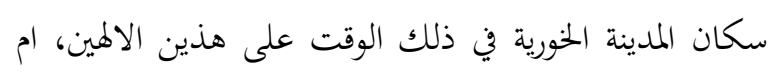

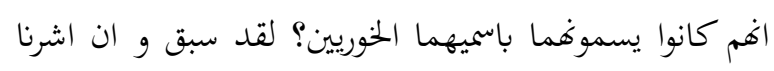


بمعنى "الولادة" في حين ان اللقب استعمل حصرا من قبل الملوك الخوريين دون البابليين و الآشوريين المتكلمين بالاكدية. غير ان كاتب هذه السطور اثبت اها و اللقب الخوري الآخر

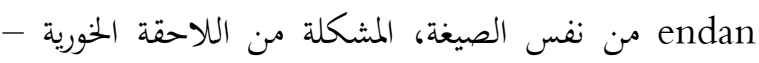

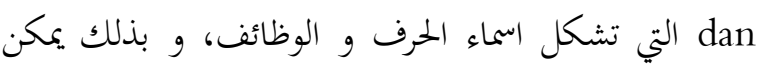

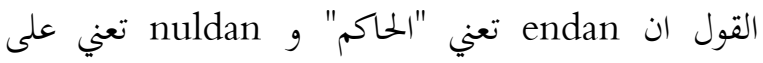
الاغلب حاكم عسكري ذو رتبة عسكرية كون -nulAhmed, ) مصطلحا عسكريا مرتبطا بالاسلحة في الخورية .(2012, 358

\section{النتائج}

يتضح مما تم عرضه و مناقشته ان العديد من الآراء

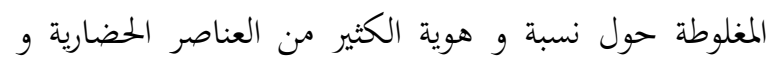

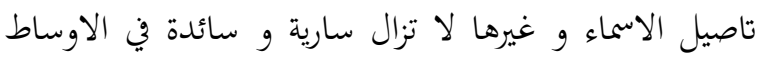
العلمية رغم مرور عقود على تصحيحها في ضوء الدراسات الحديثة و الاكتشافات التي ساهمت في تصحيح الكثير منها.

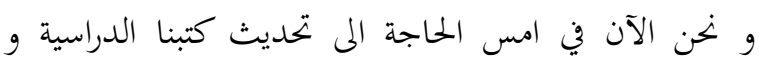
المنهجية و كذلك الموجهة الى الجمهور الاعم بالمعلومات الجديدة و الصحيحة قدر الامكان لمواكبة مثيلاتما في البلدان

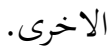

و كان في مقدمة ما تم تصحيحه تفسير اسم مدينة و اقليم اربيل و كذلك اعادة الالهة شاوشكا الى احضان مدينتها الاصلية و عاصمتها نينوى التي سرى اسمها على اها عشتار

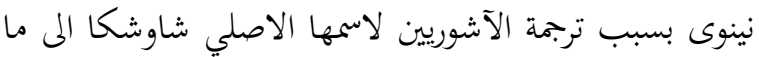
يوازيها في مجمع آلهتهم. و نفس الشيء حدث مع معبدي لمبدي

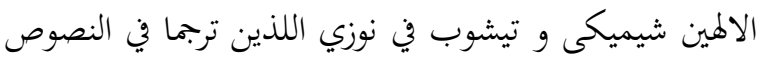

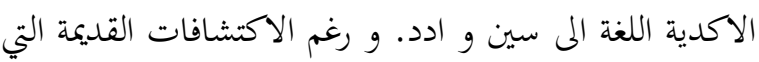
جرت في الشرقاط و اظهرت الهوية الاقدم للمدينة و سكاها، فانه ساد الاعتقاد الخاطيء بان مدينة آشور كانت منذ إنذ بدايات تاسيسها مدينة سامية اغفلت هوية الطبقات السكنية و المعابد و القطع الفنية المبكرة التي عثر عليها في اطلالها و
مثلا الباحث البارز ديوران J.-M. Durand يفسر اسم الملك الكوتي زازوم Zazum المذكور في نصوص ماري على لئى

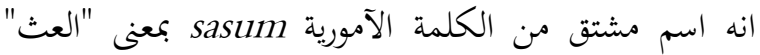
(انظر: Heimpel, 2003, 13 من دون ان يقدم تفسيرا لماذا يسمى ملك كوتي في بلاد الكوتيين البعيدة باسم آموري

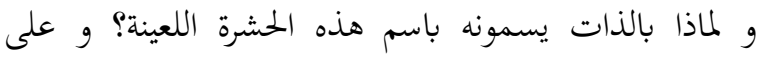
نفس المنوال يفسر اسم الملك التوروكّي زازيّا Zaziya، الذي مدهي كان من اعاظم ملوك الخوريين في هذا العصر و لم يكن كوتيا، على انه صيغة تحبيب و تدليل لنفس الكلمة الآمورية sasum اما اسم مدينة نوزي الخورية التي (Heimpel, 2003, 29)! كانت تدعى كاسور Gasur خلال الالف الثالث ق.م. و و تمت اعادة تسميتها من قبل الخوريين الذين استوطنوها في الالف الثاني ق.م.، فيعتقد ديوران انه اسم مشتق من اسم شرذمة من المرتزقة الهائمين على وجوههم في بوادي شمالى سوريا (6)-Durand, 1998, 375). نفس الشيء يقال عن اسم المملكة الخورية الشهيرة ايتابالخوم التي ظهرت في هذا العصر في مكان ما في شمالي جبال زاكروس، ربما جنوب بحيرة Ida-palhum اورمية، التي يفسرها على اها من الآمورية بمعنى "الجانب المرعب" (Charpin, 1994, 459) ذلك اتك بالرغم من العثور على ختم لملكها كتب عليه اسم المملكة

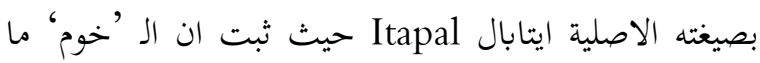
هي الا لاحقة لغوية تدل على الصفة في الخورية ( Ahmed, 12012, 350-1). و فسر اسم الزعيم التوروكّي الآخر ليدايا Lidaya على انه صيغة تصغير و تدليل للاسم الآموري

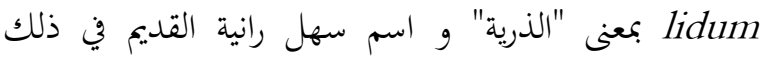
العصر اوتوم Utûm على اهما آمورية و تعني "بلاد حارس

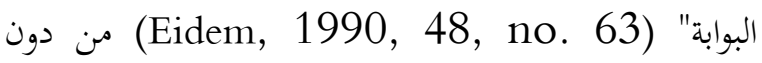
اعطاء تفاسير لاسباب هذه التسميات و لماذا بالآمورية الاكدية. و ولم يسلم اللقب الملكي الخهوري نولدان Nuldān(um)

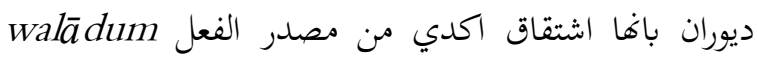


"Nabonid A," Reallexikon der Assyriologie und vorderasiatischen Archäologie, Band 9, hrsg. D. O. Edzard, Berlin.

Durand, J.-M., 1998

Les documents épistolaires du palais de Mari (LAPO), vol. II, Paris.

Edzard D. O. and G. Farber, 1974

Die Orts- und Gewässernamen der Zeit der 3. Dynastie von Ur, RGTC 2, Wiesbaden.

Eidem, J., 1990

"nuldānum/nuldānūtum- A Note on Kingship in the Zagros," $N A B U$, no. 63.

Falkenstein, A., 1956-7

Die neusumerischen Gerichtsurkunden, vols. 13, München.

Fincke, J., 1993

Die Orts- und Gewässernamen der Nuzi- Texte, RGTC X, Wiesbaden.

Forest, J.-D., 1996

Mésopotamie, L'apparition de l'Etat VIIe - IIIe Millénaires, Paris.

Grayson, A. K., 1991

Assyrian Rulers of the Early First Millennium BC I (1114-859 BC), Royal Inscriptions of Mesopotamia - Assyrian Periods, vol. 2, Toronto.

Grayson, A. K., 1987

Assyrian Rulers of the Third and Second Millennium BC (to 1115 BC), Royal Inscriptions of Mesopotamia - Assyrian Periods, vol. 1, Toronto.

Grayson, A. K., 1980-1983

"Königslisten und Chroniken, Reallexikon der Assyriologie, Band 6, Berlin.

Heimpel, W., 2003

Letters to the king of Mari, Winona Lake.

Kutscher, R., 1989

The Brockmon Tablets at the University of Haifa- Royal Inscriptions, Haifa.

Lewy, H., 1971

Assyria, c. 2600-1816 B.C., Cambridge Ancient History, Vol. 1, part 2, Cambridge.

Lewy, J., 1946

'The Late Assyro-Babylonian Cult of the Moon and its Culmination at the Time of Nabonidus, in: HUCA 19.

Luckenbill, D. D., 1927

Ancient Records of Assyria and Babylonia, vol. I, Chicago.

Moran, W. L., 1987

The Amarna Letters, Baltimore.

Poebel, A., 1942

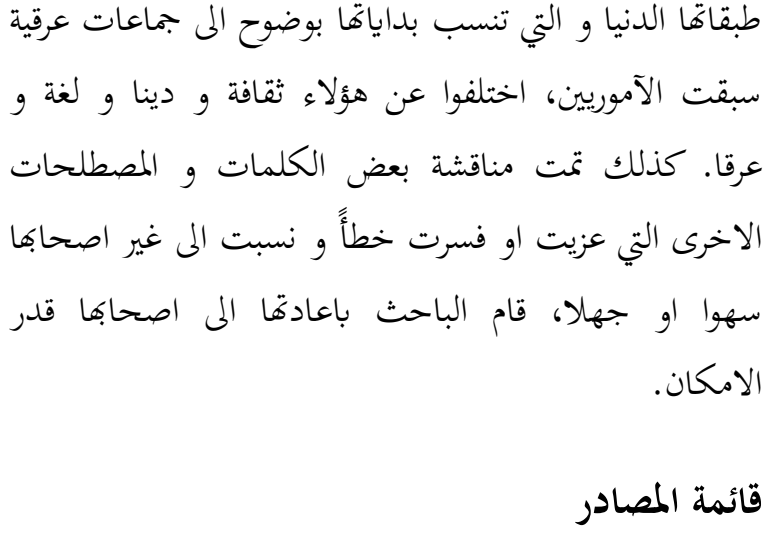

Ahmed, K. M., 2012

The Beginnings of Ancient Kurdistan, A Historical and Cultural Synthesis (c. 2500-1500 BC), Ph.D. Dissertation, Leiden.

Andrae, W., 1938

Das Wiedererstandene Assur, Leipzig.

Andrae, W., 1922

Die archaischen Ischtar-Tempel in Assur, Leipzig.

Bär, J., 2003

"Sumerians, Gutians and Hurrians at Ashur? A Re-examination of Ishtar Temples $\mathrm{G}$ and F," Iraq LXV.

Beckman, G., 1998

"Ištar of Nineveh Reconsidered," Journal of Cuneiform Studies, 50.

Charpin, D. and J.-M. Durand, 1985

"La prise du pouvoir par Zimri-Lim," Mari Annales de Recherches Interdiciplinaires 4, Paris.

Charpin, D. and N. Ziegler, 2003

Mari et le proche-Orient à l'époque Amorrite: essai d'histoire politique, Florilegium Marianum V, Paris.

Charpin, D., 2004

"Chroniques bibliographiques: 3. Données nouvelles sur la région du petit $\mathrm{Zab}$ au XVIIIe siècle Av. J.-C.," Revue d'Assyriologie et d'Archéologie Orientale, vol. 98.

Charpin, D., 1994

Review of The Shemshāra Archives 2, The Administrative Texts, by J. Eidem, Syria 71.

Damirji, M. S. B. 1987

The Development of the Architecture of Doors and Gates in Ancient Mesopotamia, Tokyo.

Dandamayev, M. A. 1998-2001

kozad.ahmad@univsul.edu.iq 
"Southern Kurdistan in the Annals of Ashurnasirpal and Today," The Annual of the American Schools of Oriental Research 8 for 1926-27.

Thompson, R. C., 1900

The Reports of the Magicians and Astrologers of Nineveh and Babylon in the British Museum, vol. II, London.

Wegner, I., 2000

Einführung in die hurritische Sprache, Wiesbaden.

Westenholz, J. G., 2004

"The Old Akkadian Presence in Nineveh: Fact or Fiction," Papers of the XLIXe Rencontre Assyriologique Internationale London, 711, July 2003, Part One in: Iraq vol. LXVI.

Whiting, R. M., 1976

"Tiš-Atal of Nineveh and Babati, uncle of ŠuSin," JCS 28.

$$
\text { تاريخ الكرد القديم، اربيل. فوزي و احد، جمال رشيد، } 1990 \text { رئ، } 1999
$$

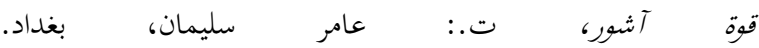

"The Assyrian King List from Khorsabad," Journal of Near Eastern Studies, vol. I, no. 3 .

Reade, J., 2005

"The Ishtar Temple of Nineveh," Iraq 67, no. 1, Proceedings of the $49^{\text {th }}$ Rencontre Assyriologiques Internationale.

Rivas, A., 2016

"Deities of Nineveh: A Look at the Temple and Rituals of Ishtar of Nineveh," TeoBiblica 2.1-2.

Roaf, M., 2003

The Architecture of the Ninevite 5 Period, in: The Origins of North Mesopotamian Civilization: Ninevite V Chronology, Economy, Society, ed. E. Rova and H. Weiss, Subartu IX, Turnhout.

Rova, E. and H. Weiss (eds.), 2003

The Origins of North Mesopotamian Civilization: Ninevite V Chronology, Economy, Society, Subartu IX, Turnhout.

Speiser, E. A., 1930

Mesopotamian Origins, Philadelphia.

Speiser, E. A., 1928

ههر له سهرهتاى دهركهوتنى زانستى ئهسيريوّلوَجييهوه و خويّندنهوهى دهقه ميّخييهكان، زوّر له

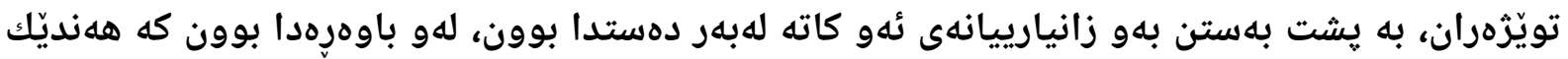

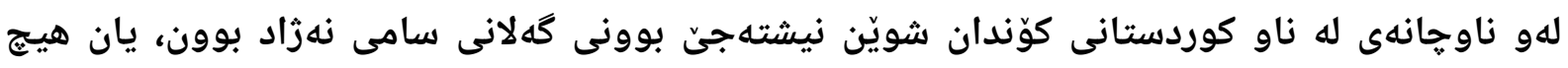

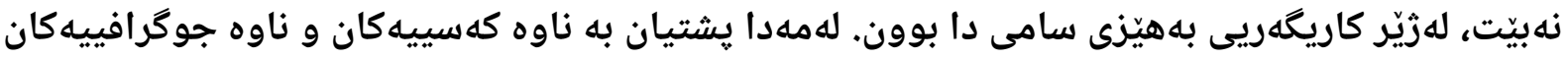

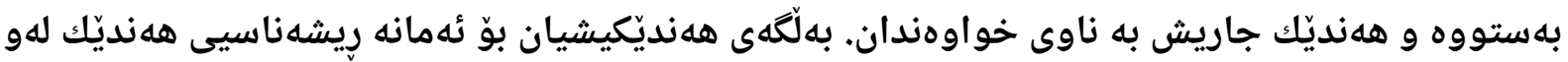
ناوه جوگرافييانه بوون كه بهشيّهيهك ريشهيان دهردههيّان كه ناوهكه به نهزاديّكى ديارى كراوهوه

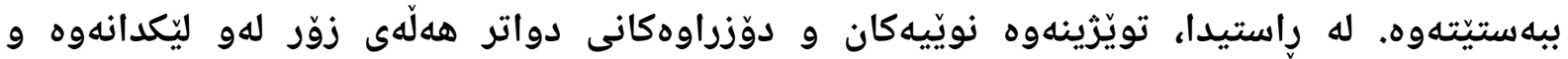

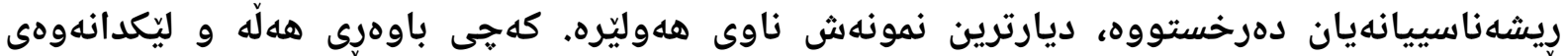

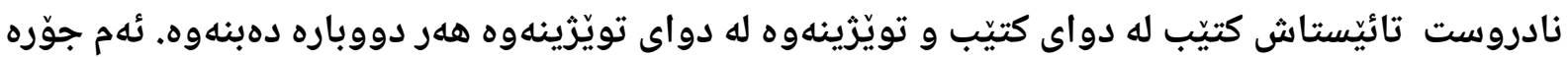

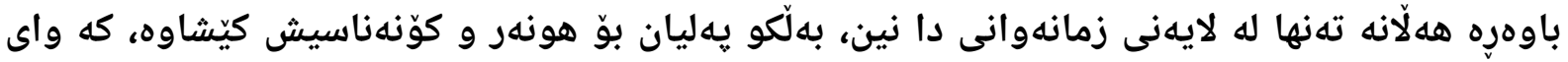

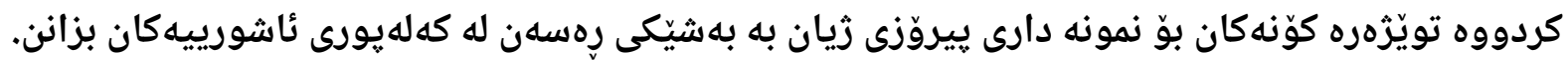

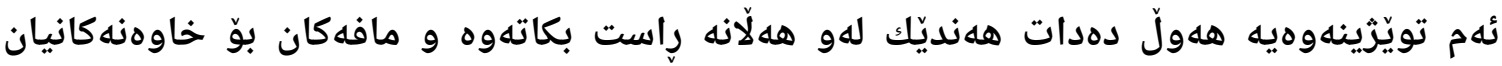

$$
\text { وشهى كليل: ميّزووى كوردستانى كوّن، سهردهمى ئاشورى، بنه جهى ناوه جوغرافييهكان، زمانى كوردى }
$$


بجلة جامعة دهوك، المجلد: 24، العدد: 1 (العلوم الانسانية والاجتماعية)، ص 146-161، 2021 (عدد خاص)

المؤتمر العلمي الدولي الثاني لقسم التاريخ-كلية العلوم الانسانية-جامعة دهوك- المنعقد بتاريخ 24-25 شباط، 2021

BETWEEN THE PLAIN AND THE MOUNTAIN, THE TRUTH ABOUT WHAT IS SEMITIC AND NON- SEMITIC IN ANCIENT KURDISTAN:

A STUDY IN LANGUAGE AND ART

\author{
KOZAD M. AHMED \\ Dept. of Archaeology, College of Humanities, University of Sulaimani, Kurdistan Region-Iraq
}

\begin{abstract}
From the beginning years of Assyriology and the decipherment of cuneiform inscriptions, many authorities, depending on the then available material, thought that some territories within Ancient Kurdistan to have been Akkadian / Amorite, or at least, under their heavy ethnic influence. They depended on the formation of such beliefs on onomastic and toponymic data in addition to some divine names. In many cases toponyms have been unintentionally etymologized in such a way that connects them to a certain ethnicity. In fact, recent researches and new discoveries showed that many of these etymologies were incorrect. The best known example is the name of Erbil. Nonetheless, the mistakes keep spreading and repeating itself in popular literature by laymen. Such beliefs are not restricted to linguistics, however, they are found in arts and archaeology too, such as the sacred tree of life which is attributed by many to the Assyrians and consider it a pure component of the Assyrian heritage.
\end{abstract}

This article aims at the correction of some of these beliefs.

Keywords: Kurdistan, The Ayrians, Erbil, The Hurrians, Subarians, Zaziya, Arrapha. 
بجلة جامعة دهوك، المجلد: 24، العدد: 1 (العلوم الانسانية والاجتماعية)، ص 146-161، 2021 (عدد خاص)

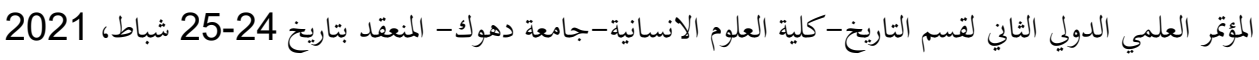

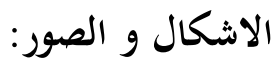

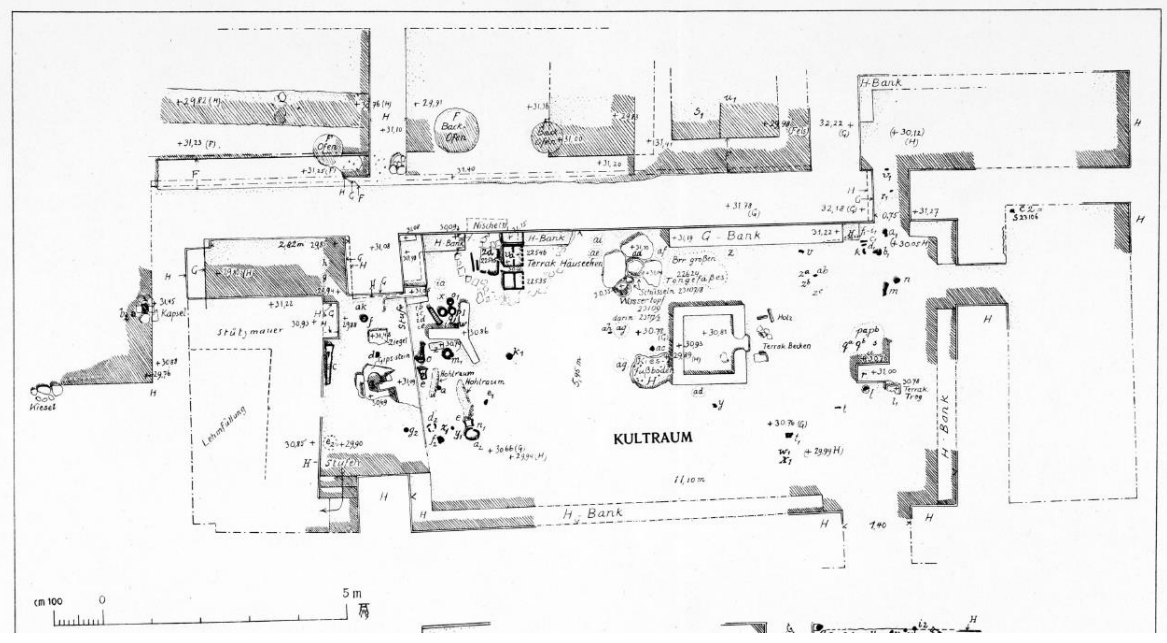

الشكل رقم 1: مخطط معبد عشتار القديم في آشور، عن: . Andrae, 1922, pl.

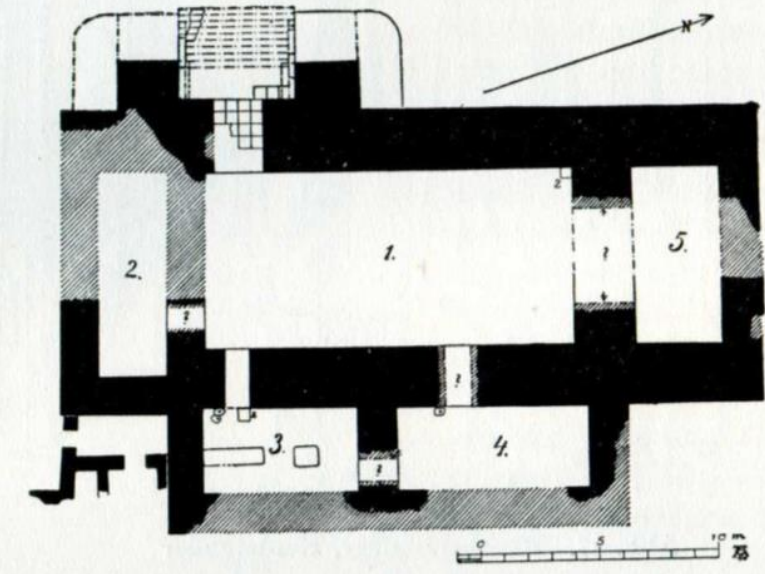

Andrae, op. cit., fig. 38. الشكل رقم 2: خغطط معبد عشتار القديم في آشور، عن 
مجلة جامعة دهوك، المجلد: 24، العدد: 1 (العلوم الانسانية والاجتماعية)، ص 146-161، 2021 (عدد خاص)

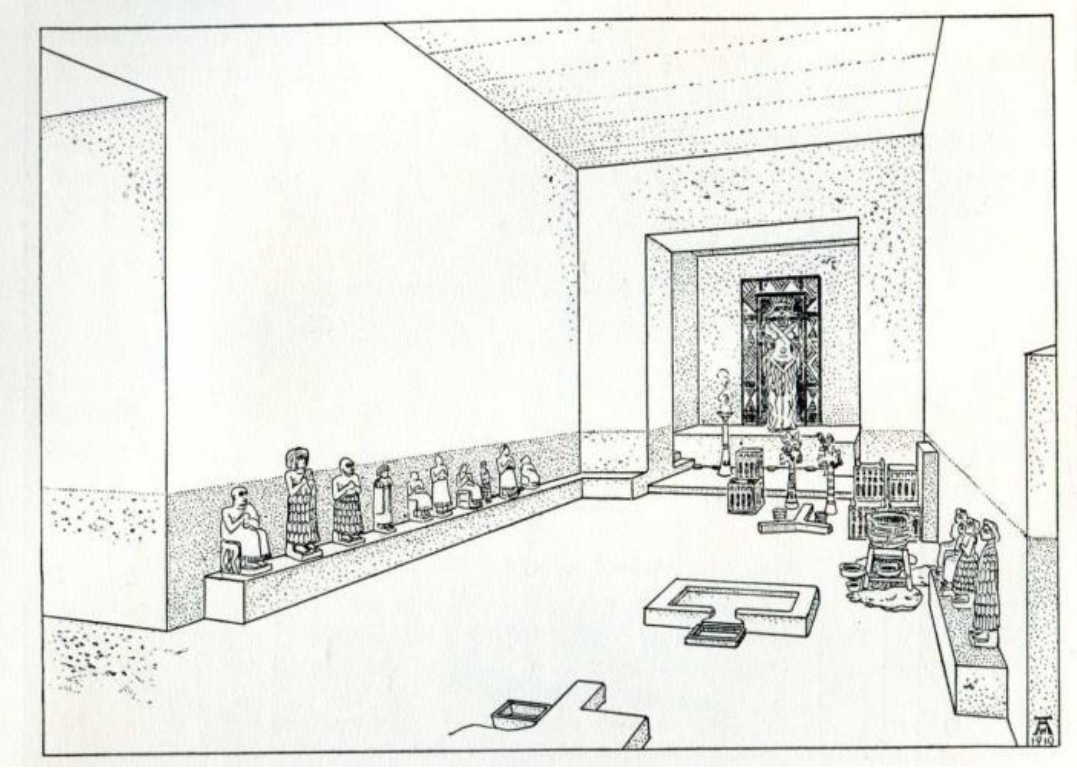

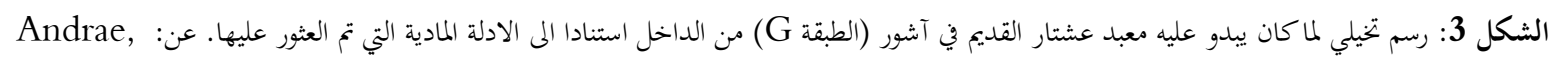
op. cit., fig. 34.

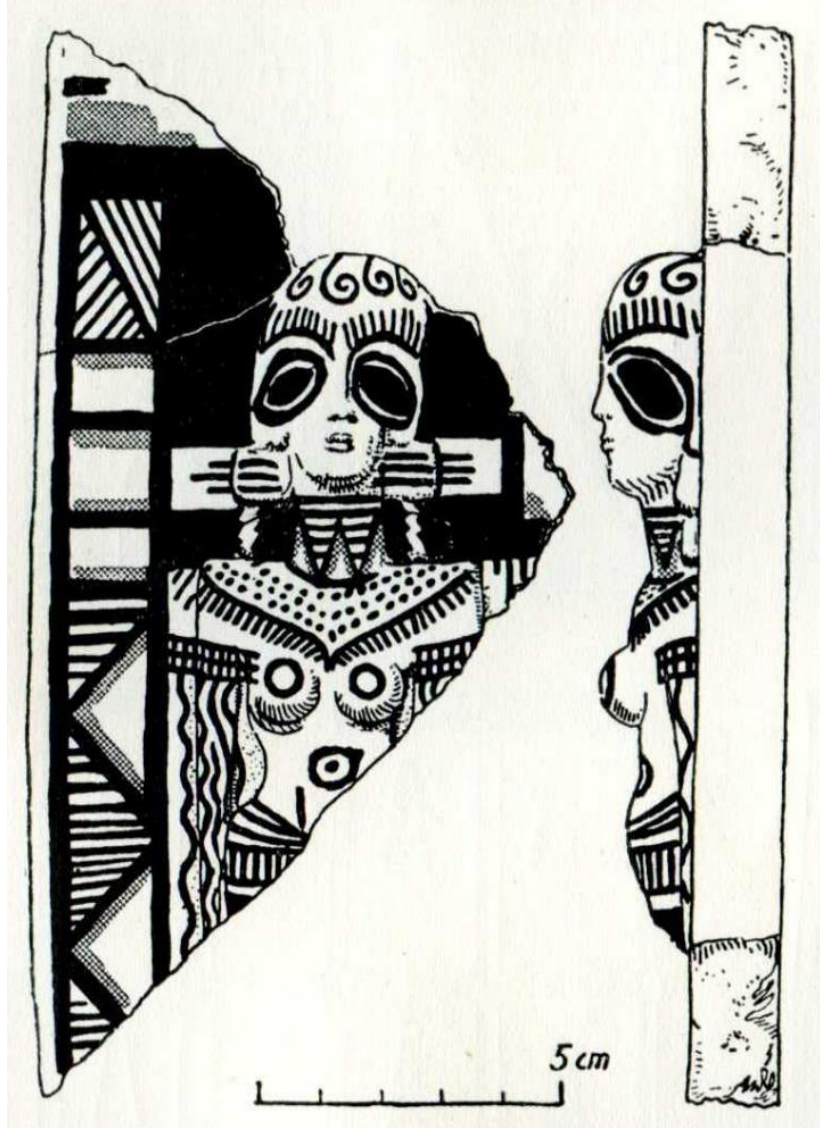

الشكل رقم 4: كسرة تُثال فخاري من معبد عشتار القديع تثثل الالهة عشتار اغلب الظن. عن: .Andrae, op. cit., fig. 36 
بجلة جامعة دهوك، المجلد: 24، العدد: 1 (العلوم الانسانية والاجتماعية)، ص 146-161، 2021 (عدد خاص)

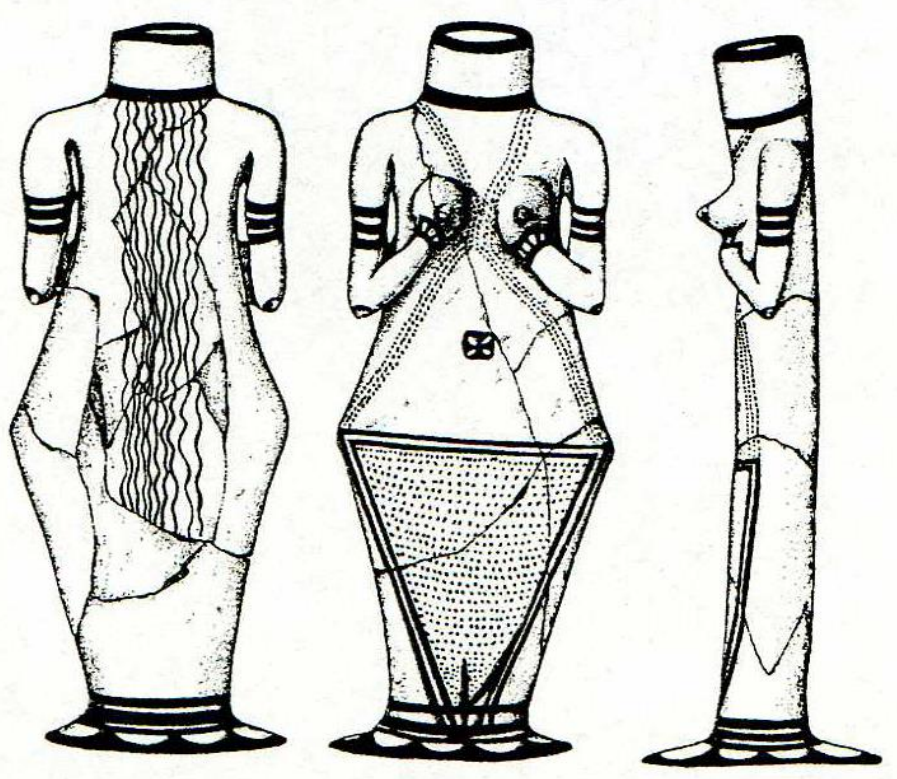

Forest, 1996, 33 الشكل 5: اناء فخاري على شكل انتوي من يارم تبة 2 من عصر حلف، عن
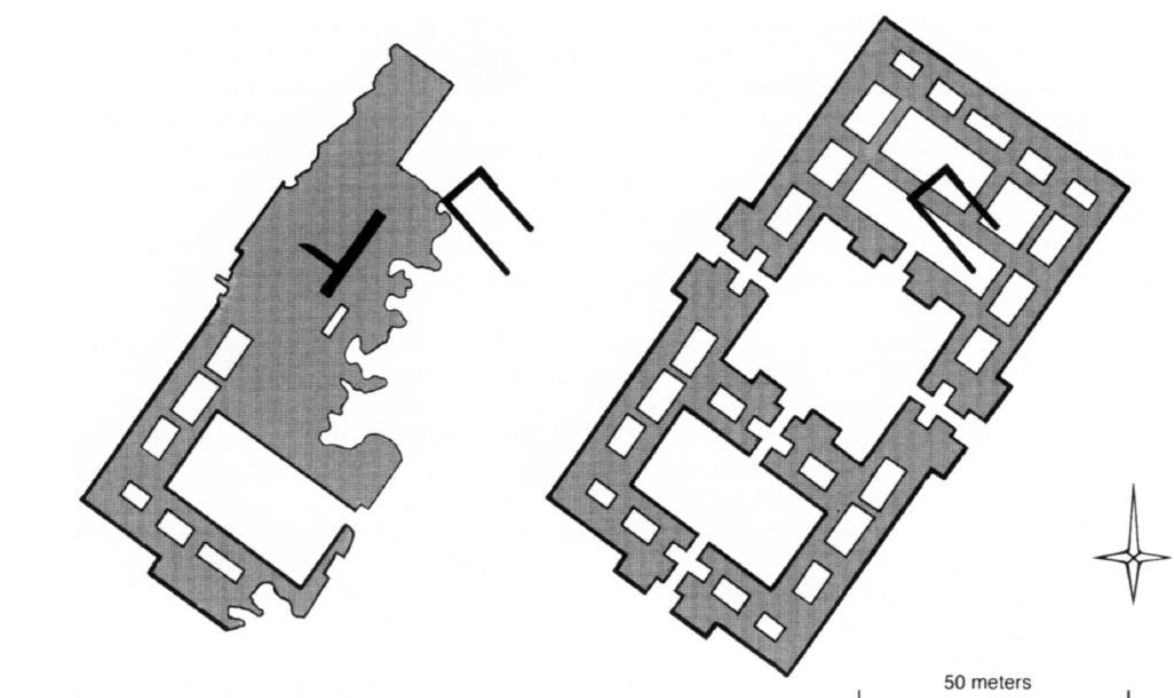

الشكل 6: خخطط معبد شاوشكا / عشتار نينوى من عصر ششي-ادد و تحته بقايا المعبد من عصر نينوى 5. عن: .Reade, 2005, 365 